\title{
Parents' Perceptions and Awareness of Cyberbullying of Children and Adolescents
}

\author{
by \\ Bryan D. Clarke
}

B.S., Saint Lawrence University, 2007

M.S., Antioch University New England, 2010

\section{DISSERTATION}

Submitted in partial fulfillment of the requirements for the degree of Doctor of Psychology in the Department of Clinical Psychology at Antioch University New England, 2013

Keene, NH 


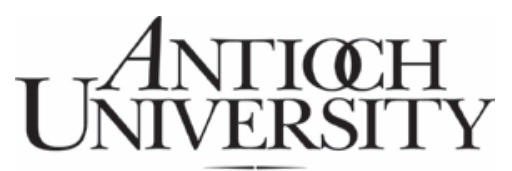

N E W E N L A N D

Department of Clinical Psychology

\section{DISSERTATION COMMITTEE PAGE}

The undersigned have examined the dissertation entitled:

\section{PARENTS' PERCEPTIONS AND AWARENESS OF CYBERBULLYING OF CHILDREN AND ADOLESCENTS}

presented on November 4, 2013

$$
\text { by }
$$

\section{Bryan D. Clarke}

Candidate for the degree of Doctor of Psychology and hereby certify that it is accepted*.

Dissertation Committee Chairperson:

Gargi Roysircar-Sodowsky, PhD

Dissertation Committee members:

William Slammon, PhD

Martin LaRoche, PhD

Accepted by the

Department of Clinical Psychology Chairperson

Kathi A. Borden, PhD

on $11 / 4 / 13$

* Signatures are on file with the Registrar's Office at Antioch University New England. 


\section{Dedication}

To my parents, David and Linda Clarke.

I could not have survived this long journey without your support, encouragement and unconditional love. You were always there to help me when I needed it the most.

For teaching me how to enjoy life even when times are difficult, and for being the ultimate role models, I dedicate this paper to you.

Love you both! 


\section{Acknowledgments}

First and foremost, I would like to thank my dissertation chair, Dr. Gargi Roysircar, for all of her mentorship and guidance throughout this endeavor. Without her support, this dissertation would not have been possible. She challenged me to think critically, set high standards, and most importantly, challenge myself throughout the process. Her passion for her students is evident in all that she does at Antioch, and as a result I can proudly submit this dissertation. Thank you Gargi!

Next, I would like to thank my other committee members, Dr. Bill Slammon and Dr. Martin LaRoche. Thank you not only for your support of this dissertation, but also for being instrumental in my growth as both a psychologist and as a person. Bill, your thoughtfulness, curiosity, and, most importantly, your friendship, have helped me grow and transform myself throughout graduate school. From our first assessment class to our time in Winchester to now, you have always challenged me to think critically, take chances, and been there along the way if I were to falter. Martin, muchísimas gracias por tomar un chance conmigo y aceptarme a trabajar en MEHC contigo. Palabras no pueden expresar el impacto que esa experiencia ha tenido en mi vida y lo tanto que tu voz y tu influencia aparece en mi trabajo. También, gracias por enseñarme el sendero de cómo ser un psicólogo que incorpora cultura y justicia social en todo que hago.

I would also like to thank all my Antiochian peers, with a special thanks to Kerry Nelligan, John Lynch, Vince Pignatiello, Meg Richard, Randi Hirschberg, and my dissertation seminar group (Amithea Love, Jen Aufiero and Sheeba Thomas). I am so lucky to have had you all by my side because I don't know what I would do without you. A big thank you also goes out to my Martha Eliot fellow practitioners for support, laughter, and many great memories. Thank you Kim Santora, Margaret Frempong, Ernesto Berkowitz, Sarah Lowe, Kara Lustig, and Erin 
Rowe!

To my West Coast Children's Clinic Safety Buddies: Matt Wong, Ellie Pelc, Madelyn Chatton, Amy Gruber and Melanie Berry — Thank you for becoming my Bay Area family, pushing me to grow, and always keeping me "safe" at my predoctoral internship in San Francisco, far away from my home in New Hampshire. Also, a big thank you to others from the West Coast Children's Clinic: Erin Rosenblatt, Margaret Nettles, Barbara Lynch, and the front desk ladies (Enrika and Donna). You all played a bigger role than you could have ever imagined in my becoming the clinician I am today. An extra special thanks to Roberto Lascano who encouraged me to continually think outside of the box, work outside of my comfort zone and, ultimately, to become the type of clinician I never knew I could be. This dissertation would never have been finished if not for Roberto's continued support and holding me accountable for progress on my dissertation.

Lastly, I would like to thank Simon Therrien-Denis, Renée Clarke and Michael Ansaldi, Chris Kirwin, Grandma and Pappa, Mémère and Pépère, Nick Muccioli and Taylor Sharkey, Mike McDonald, the Gerry/Cherry Street guys, Melissa Chen, The Flying Pig Café in San Francisco (especially Will and Sara for letting me dissertate there all day long), Dan Bassett, Doug Trudel, Michael Drumm, Lee Lemoine, Tavata Speiss, Sarah Fernandez, Justin Bauer, Dr. Steven White, Paulina Espinosa, Veronica Artavia Diaz, Greg and Leanne McHale, and the rest of my friends and family for all of your love and support. I will forever appreciate everything you've ever done for me - places to crash when I needed somewhere to stay, distractions when I was stressed, advice whether or not I wanted to hear it, and the many MANY experiences and memories that will never be forgotten. I am so fortunate to have each and every one of you in my life, never underestimate the profound influence each of you has had on 
making me the person I am today. Thank you everyone! 


\section{Table of Contents}

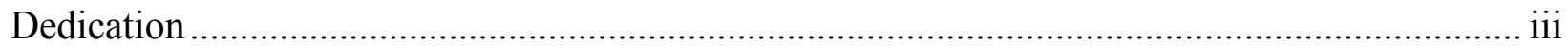

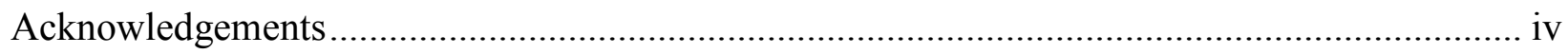

Table of Contents ............................................................................................................

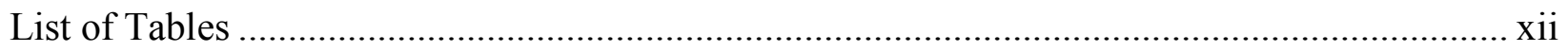

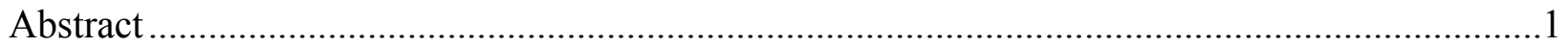

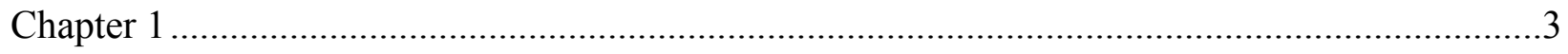

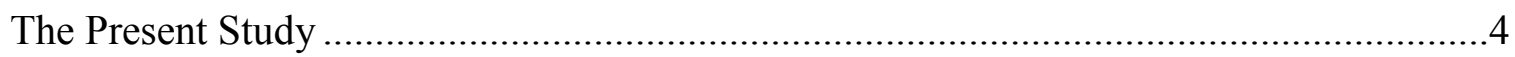

Statement of the Problem...........................................................................................

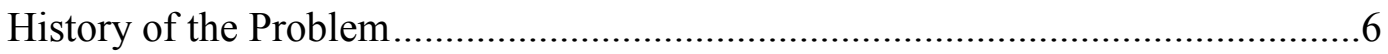

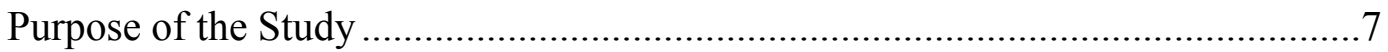

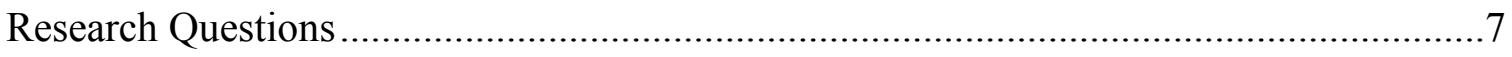

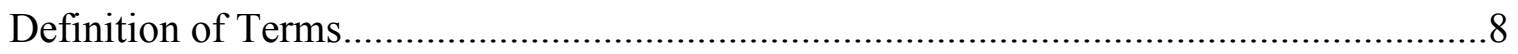

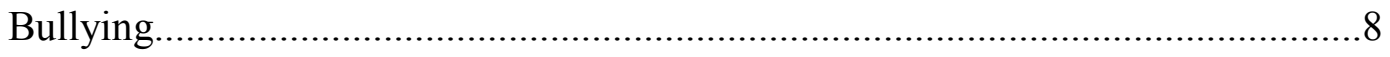

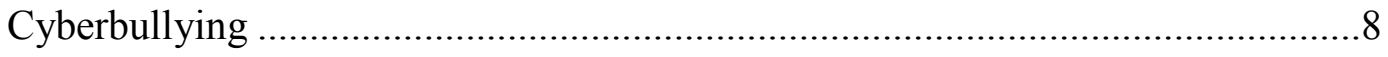

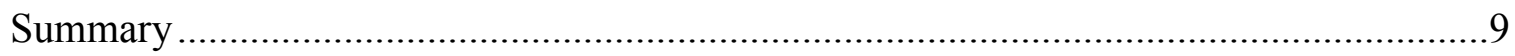

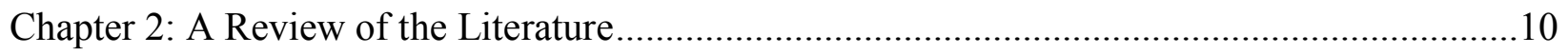

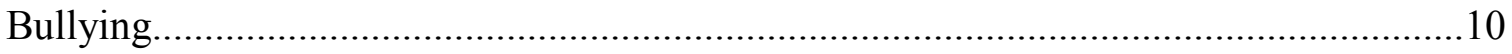

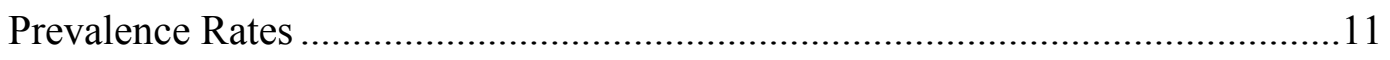

Bullying in Minority Populations ........................................................... 11

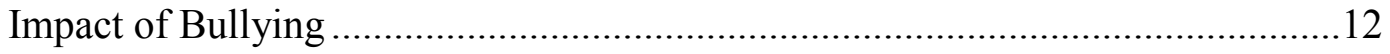




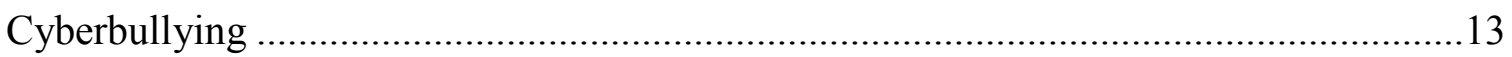

Reported Incidents of Cyberbullying .............................................................13

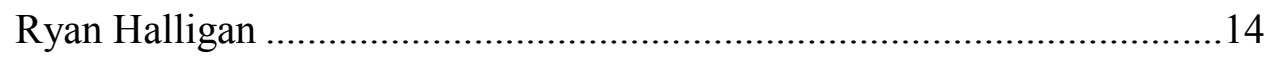

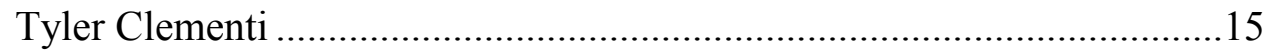

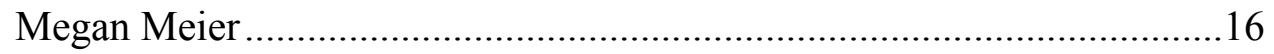

Prevalence Rates of Cyberbullying ...................................................................

Male versus Female Victims.......................................................................18

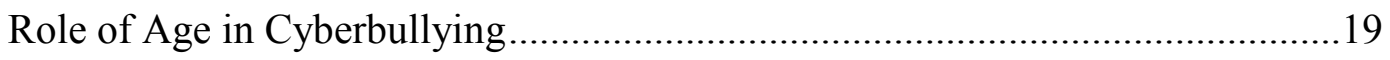

Cyberbullying amongst Minority Populations......................................................20

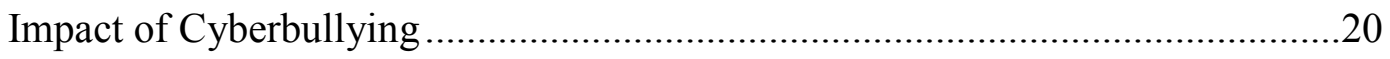

How Cyberbullying is Carried Out .................................................................21

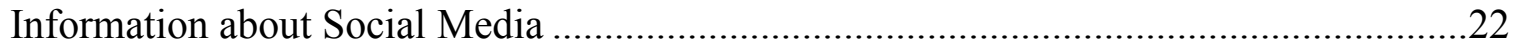

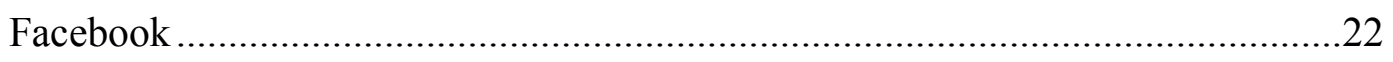

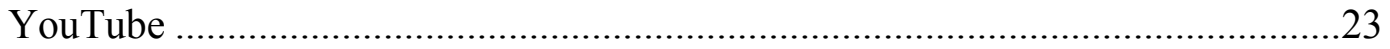

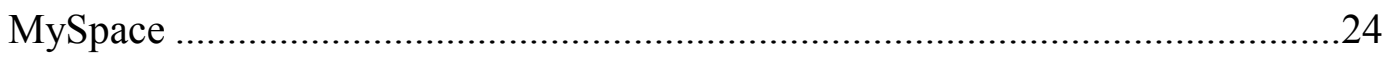

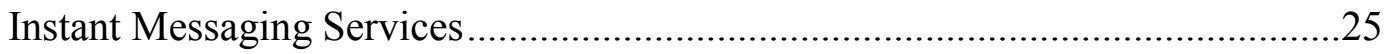

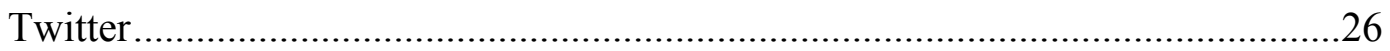

Common Strengths and Weaknessesof Social Media............................................27

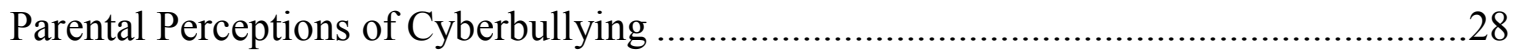

School Personnel's Perceptions of Cyberbullying .........................................................29

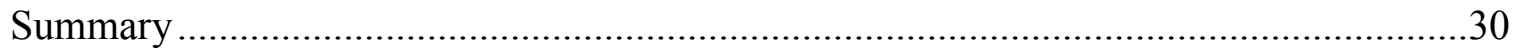

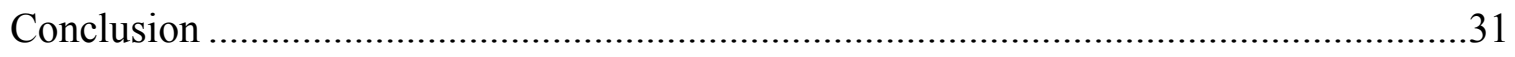

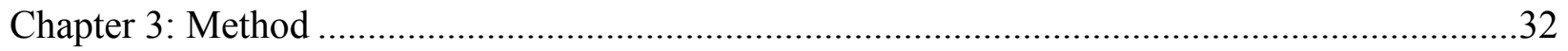




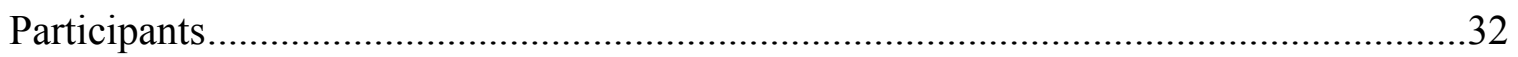

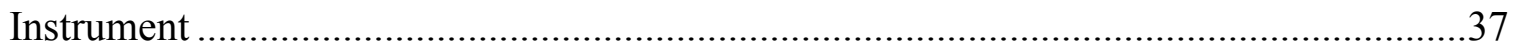

Parents' Beliefs about Extent of Cyberbullying ...............................................38

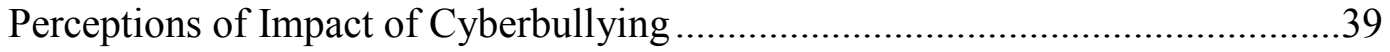

Family Practices Regarding the Internet.....................................................39

Familiarity with Cyberbullying Mediums ..................................................40

Acquisition of Knowledge about Cyberbullying .........................................40

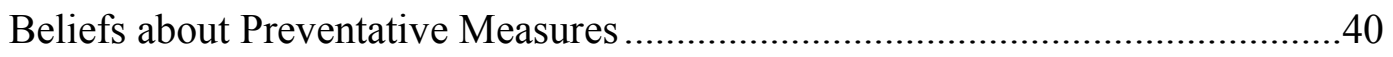

Open-ended Questions .......................................................................... 41

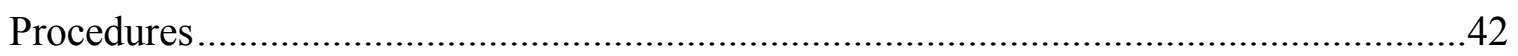

Ethical Research Practice...............................................................................4

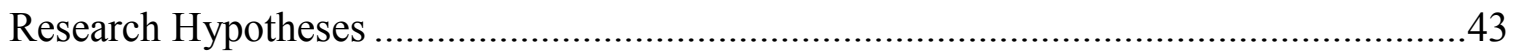

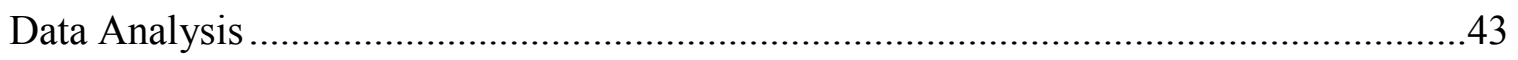

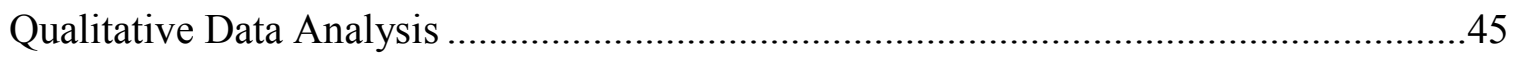

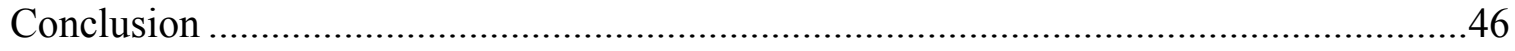

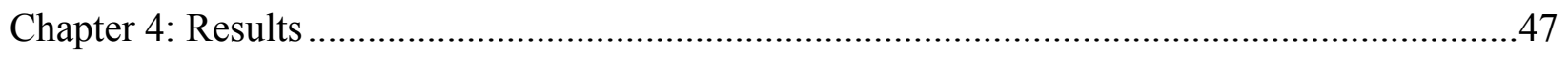

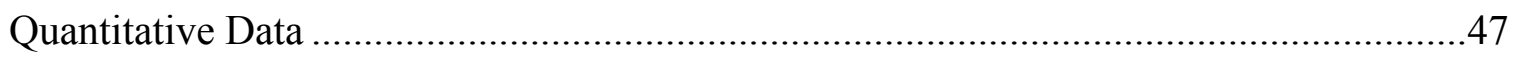

Internal Consistency Reliability ...........................................................4 47

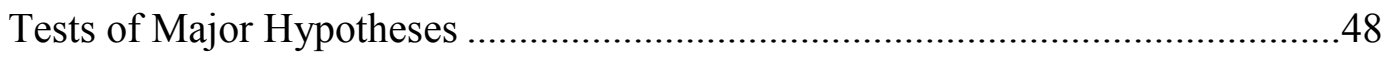

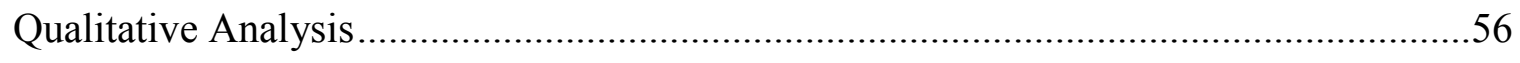

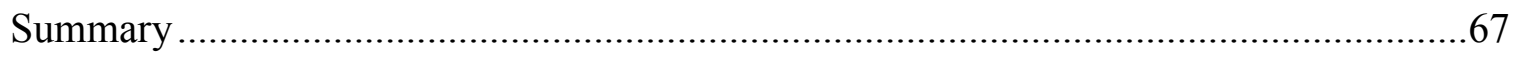

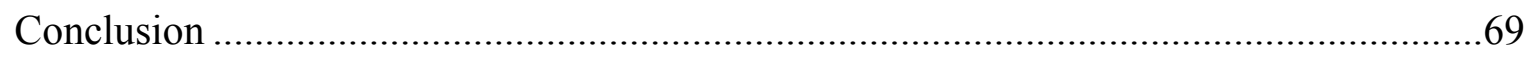




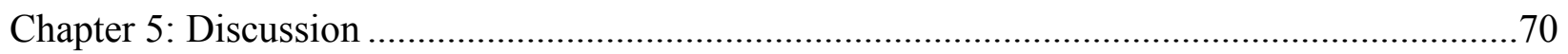

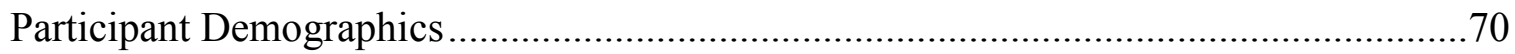

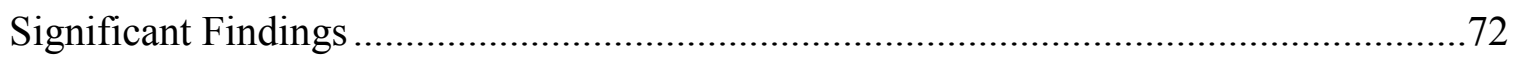

Beliefs of the Extent of Cyberbullying ...........................................................72

Cyberbullying versus Traditional Bullying ........................................................73

Age and Familiarity with Cyberbullying Mediums ..............................................73

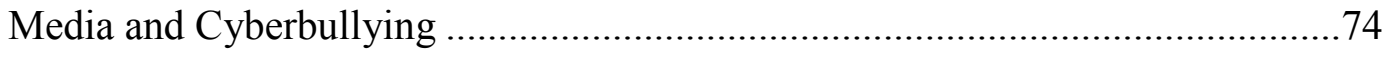

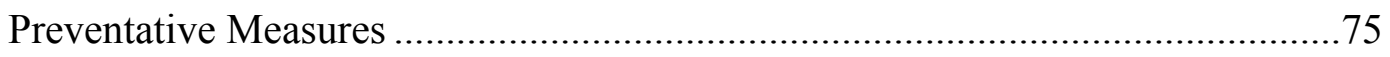

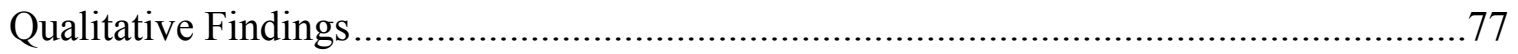

What Cyberbullying means to Caregivers ............................................................77

How Respondents See Cyberbullying as a Problem..............................................79

How Caregivers Monitor their Child's Use of the Internet ....................................79

Restrictions Caregivers Place on their Child's use of the Internet ........................80

Other ways Caregivers Learned about Cyberbullying ..........................................81

Different Types of Media through which Cyberbullying Occurs...........................81

Obstacles Prohibiting Youth from Getting Help .................................................81

Additional ways Caregivers Think Cyberbullying can be Addressed .....................82

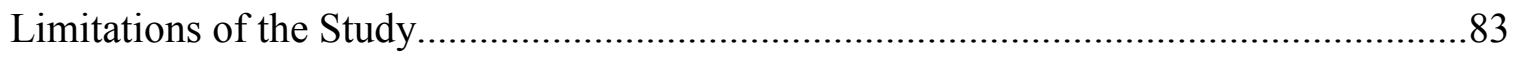

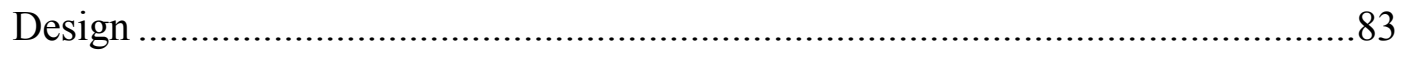

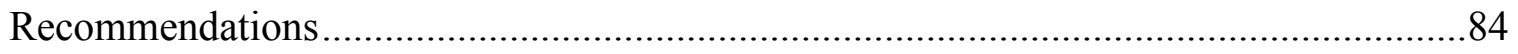

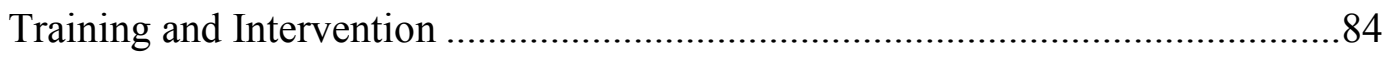

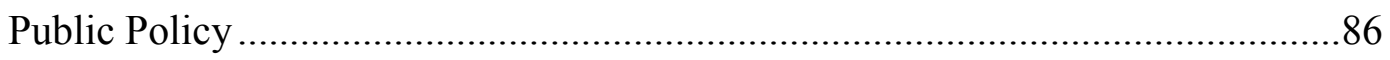

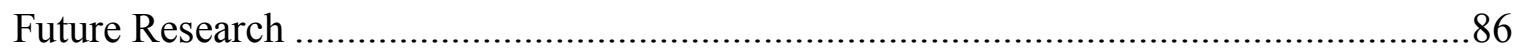


Summary .88

References.. .90

Appendix A: Demographic Questionnaire. .101

Appendix B: Cyberbullying Questionnaire 103

Appendix C: Informed Consent. .108 


\section{List of Tables}

Table 1: Participants who live in the United States by State

Table 2: Marital Status

Table 3: Participants' Race or Ethnicity

Table 4: Class and Income

Table 5: Reliability of Six Dimensions

Table 6: Cyberbullying Subscale Means and Standard Deviations.

Table 7: Beliefs About Extent of Cyberbullying.

Table 8: Beliefs of Extent and Impact of Cyberbullying and Traditional Bullying .51

Table 9: Age and Familiarity with Cyberbullying Mediums

Table 10: Age and Family Internet Practices

Table 11: Media and Impact of Cyberbullying

Table 12: Media and Prevention of Cyberbullying

Table 13: Preventative Measures' Perceived Impact on Prevention of Cyberbullying.

Table 14: Different Ways Caregivers Monitor their Child's use of the Internet..... .57

Table 15: Different Restrictions Caregivers Place on their Child's use of the Internet .58

Table 16: Other Ways Caregivers Learned about Cyberbullying.....

Table 17: Different Types of Media through which Cyberbullying Occurs.

Table 18: Obstacles Preventing Youths from Getting Help

Table 19: Additional Ways Respondents Think Cyberbullying Can be Addressed .64 
Table 20: What Cyberbullying Means for Respondents ......................................................66

Table 21: How Respondents see Bullying as a Problem..............................................................67 


\begin{abstract}
New communication technology, including Facebook, Twitter, cell phones, and instant messaging, has connected people in ways that were unknown. The benefits for people contacting each other at a moment's notice are profound; however, these benefits bring new risks, such as, "cyberbullying," which is a development from traditional bullying. Cyberbullying is the use of the internet to perpetrate deliberate, repeated, and hostile behavior by an individual or group that is intended to harm another person or others. Cyberbullying affects large numbers of children and adolescents, but its psychological impact is not clearly understood, apart from people hearing anecdotes on the suicides of cyberbullied youth. Furthermore, parental perceptions of cyberbullying, including its extent and impact, are largely unknown. The present study examined parents' $(N=99)$ perceptions and awareness of cyberbullying (PPAC) of children and adolescents. An online PPAC survey included a Likert-type questionnaire and several open ended questions interspersed within the instrument that addressed research hypotheses and questions on cyberbullying of school and undergraduate students. The PPAC showed high internal consistency reliability. Significant findings included the following: participants believed that cyberbullying is a problem that needs to be addressed; that traditional bullying is more harmful than cyberbullying; that participants were more likely to have learned about cyberbullying from television than any other media; that they were familiar with social media, particularly Facebook and Twitter; and that school and law involvement was believed to be more helpful prevention than parental involvement. Participants' comments richly expanded on their answers to the quantitative items. Using qualitative thematic analyses, many themes emerged, the most common being: fear is a major obstacle preventing youth from getting help; awareness needs to be raised about cyberbullying; and talking with other parents plays a major role in
\end{abstract}


learning about cyberbullying. The discussion of the results and their implications provide an understanding of parental beliefs, attitudes, and needs with regards to cyberbullying and the preventative and intervention methods that could be used by them, schools, and the law. Importantly, parents indicated low self-efficacy beliefs, a helpless observer stance, or an attribution blame orientation toward other parents about the advent of cyberbullying. There is a discussion of educational programming for students and parents, policy-making actions, future directions in research, and limitations of the study.

Keywords: cyberbullying, parents, social media, public policy, prevention, monitoring, restrictions 
Parents' Perceptions and Awareness of Cyberbullying of

Children and Adolescents

\section{Chapter 1}

Researchers in many fields, such as, education, health, school psychology, and psychiatry, have investigated the impact of bullying on victims. It is believed that students who are bullied are more likely to experience depression, low self-esteem, health problems, poor grades, and suicidal thoughts than their peers who have not been bullied (Dehue, Bolman, \& Völlink, 2008; Katzer, Fetchenhauer, \& Belschak, 2009; Smith, Mahdavi, Carvalho, \& Tippett, 2006; Ybarra, Diener-West, \& Leaf, 2007). Cyberbullying is a relatively new phenomenon compared to traditional physical and verbal bullying in school hallways and playground. However, cyberbullying poses many of the same risks for its victims as do traditional forms of bullying (Diamanduros, Downs, \& Jenkins, 2008; Katzer et al., 2009; Smith et al., 2008; Ybarra et al., 2007). Specifically, victims of cyberbullying are "significantly more likely to concurrently report depressive symptomatology, life challenge, interpersonal victimization, deficits in social skills, and harassing others online themselves" than those children who have not experienced cyberbullying (Ybarra, Mitchell, Wolak, \& Finkelhor, 2006 as cited in Ybarra, Diener-West, \& Leaf, 2007, p. 42).

Further, compounding the problem of cyberbullying is the importance and high frequency of internet and other forms of electronic communication with teens (Grohol, 2008). Adolescents are navigating their social worlds through electronic means (Grohol, 2008). A new kind of internet communication dynamic has emerged, such as the management of elaborate networks of friends and acquaintances; a socialization process that is often in the public domain; difficulties determining the authentic identity of others; and being in a state of perpetual "connectedness" 
with peers (Belsey, 2004; Goddard, 2008; Grohol, 2008; Li, 2006; Willard, 2004). These electronic communication dynamics have created an environment where cyberbullying can be an anonymous, private, or public attack that occurs at any time of the day.

\section{The Present Study}

In the present study, data were collected through an online questionnaire on the awareness that caregivers have about cyberbully victimization of children and adolescents. These individuals were eligible to participate if they were parents, grandparents, guardians, or caregivers between 22 and 65 years of age and were raising school-aged children or undergraduate students. Because empirical research on cyberbullying is limited in the professional literature, this was an exploratory study on a needs assessment to gain perspective on caregivers' awareness of: cyberbullying in general; how cyberbullying takes place and its extent; how cyberbullying has an impact on child and adolescent victims' lives; how cyberbullying compares to conventional bullying; and how cyberbullying might be handled by parents, schools and the law.

\section{Statement of the Problem}

Awareness that bullying, in general, is a significant problem in schools has led to a surge in interest in understanding and preventing bullying among school children in the United States and internationally (Williams \& Guerra, 2007). This interest has lead to a plethora of research, which has helped to guide the formulation and implementation of interventions in various state and school policies in this nation to curb bullying in schools (Cyberbullying Research Center, 2012). Despite school and state efforts to prevent or reduce bullying, recent years have seen an increase in bullying in another venue-through the internet that extends beyond school grounds and outside of school jurisdiction and less easy to track down. This type 
of bullying has since been labeled "Cyberbullying," a term that was first introduced by Bill Belsey, a Canadian educator and leader of the annual National Bullying Awareness Week (Walker, 2010).

William and Guerra (2007) stated that "With an estimated 45 million children between the ages of 10 and 17 in the U. S. alone using the internet every day, social interactions have increasingly moved from personal one-to-one contact in the school room to virtual contact in the chat room, and Internet bullying has emerged as a new and growing form of social cruelty" (p. 15). As the internet has become more popular with the youth, the potential benefits and risks of the internet to adolescent mental health are being increasingly recognized (Ybarra et al., 2007). For benefits, the internet has allowed for an increased connectivity with friends and family as well as an increased access to important information, including health information (Ybarra et al., 2007).

Currently, school officials have difficulty figuring out how to intervene when they become aware of cyberbullying because this type of bullying often occurs off school grounds and outside of school time (Dehue et al., 2008; Kowalski \& Limber, 2007; Smith et al., 2008). An understanding of the nature of cyberbullying will help school officials to address this problem because more than half of the children and adolescents do not report incidents of cyberbullying to their parents or other adults (Diamanduros et al., 2008).

The advent of the internet has made it more difficult for parents to monitor their children's interactions with others (Juvonen \& Gross, 2008). In the past, parents would know who their child was talking to or with whom they were spending time. This has become more difficult with the increased use of instant messaging, email, and social networking. One medium of communication that has particular interest to the present study is social networking websites. 
Social networking websites, such as MySpace and Facebook, are a form of media that is used in cyberbully attacks (Williams \& Merten, 2008). Social networking websites are wildly popular and play an important role in adolescent socialization. Adolescents are communicating through these social networking websites rather than through landline telephones. Social media allow people to communicate with others in a public forum. Individuals can present their identity in any manner they wish, such as giving oneself any name, age, sex, or affiliation (Williams \& Merten, 2008). The integration of instantaneous communication, public forum, and freedom of self-identification is an exciting freedom with appeal to adolescents. Cashmore (2006) illustrates this point by saying "MySpace, a social networking site for tweens and teens, is one of the most popular websites in the United States and reportedly surpassed 100 million users in August 2006" (p. 1). This popularity makes social networking websites particularly popular places for cyberbullying (Goddard, 2008). However, parents' perceptions and awareness of what happens on social networking sites is fairly limited (Juvonen \& Gross, 2008), which was also an assumption of the present study.

\section{History of the Problem}

While research has noted the many negative effects of cyberbullying on youth (Bauman, 2010; Juvonen \& Gross, 2008; Tokunaga, 2010; Ybarra, 2004), there is considerably less data surrounding the particular media used to commit cyberbully attacks. Diamanduros et al. (2008) stated that "Understanding the essential role that technology has in the social networking of children and adolescents will give parents and educators insight into the degree to which students rely on technology to socialize and the potential dangers that are associated with such behavior" (p. 695). While some research has been conducted to examine the role of the various forms of media used by adolescents to socialize (e. g., instant messaging, email, text messaging; Patchin 
\& Hinduja, 2010), caregivers' awareness of the use of such media by their children is in need of research.

\section{Purpose of the Study}

The purpose of the study was to investigate parents' perceptions and awareness of cyberbullying: of the various processes of cyberbullying, such as, how these occur and how parents become aware of the risks and results of cyberbullying. It has been found that many young people are fearful of telling others about being bullied for fear of the bullying increasing in frequency and severity (Belsey, 2004). They are also afraid of reporting to parents for fear that their parents will take away their cell phones, laptops, and/or internet access (Belsey, 2004). Additionally, because cyberbullying often occurs outside of school, it has become difficult for parents and teachers to identify victims of cyberbullying or monitor bullies. Many of these victims are often left to suffer alone, unbeknownst to the prominent adults in their lives, their parents and teachers. If parents are able to better understand their children's risks for and experiences of cyberbullying, then it follows that they might also be able to better identify cases of cyberbullying, intervene before serious problems are manifested, or implement preventative measures to limit cyberbullying.

\section{Research Questions}

The present study attempted to address a gap in cyberbullying research by answering the following research questions.

1. Do parents feel like cyberbullying is a problem that should be addressed?

2. How do parents perceive child and adolescent victims' experiences of cyberbullying?

3. What awareness do parents have of the media used to conduct cyberbullying (e.g., Facebook, instant messaging, etc.) of children by children? 
4. How have parents learned about cyberbullying and its impact on children?

5. What do adults perceive to be parental, micro-level (e.g., schools, local communities), and macro-level (broader societal action, such as that of the legal system, policy-making) preventative measures that can mitigate the occurrence of cyberbullying?

\section{Definition of Terms}

\section{Bullying}

Bullying is defined as being "repeated intimidation, over time, of a physical, verbal, and psychological nature of a less powerful person by a more powerful person or group of persons" (Slee, 1996, p. 64). Traditional forms of bullying are identified as being physical, verbal, relational (e. g., social exclusion) or indirect (e. g., rumor spreading) in nature (Smith et al., 1999). Due to the daily opportunities for these types of interactions, schools are a prime location for bullying. This has led to approximately $70 \%$ of youth reporting that they have been bullied at some point during their school careers (Hoover et al., 1992).

\section{Cyberbullying}

Cyberbullying involves the use of information and communication technologies, such as e-mail, cell phones, smart phones, tablets, and pager text messages, instant messaging (IM), defamatory personal Web sites, and defamatory personal polling Web sites, to support deliberate, repeated, and hostile behavior by an individual or group that is intended to harm another person or others (Belsey, 2004; Harcey, 2009). Ybarra et al. (2007) found that, similar to bullying that occurs face-to-face, victims of cyberbullying are significantly more likely than their peers to concurrently report psychosocial problems. These psychosocial problems include depressive symptomatology, life challenge, interpersonal victimization, deficits in social skills, and harassing others online themselves (Ybarra et al., 2007). Research, while limited, has focused on 
these outcomes of cyberbullying. However, there is relatively little research on examining parents' perceptions and awareness of cyberbullying.

\section{Summary}

The medium through which adolescents communicate and socialize has changed dramatically in recent years. Despite its many benefits and increased possibilities for connectedness among people, the internet has become a haven for innovative forms of negative interpersonal behaviors that comprise what has been termed "cyberbullying." This often occurs via Facebook, MySpace, YouTube, text messaging, and instant messaging. There is often low awareness in parents that cyberbullying is taking place because its venues are hidden electronics, making it difficult for parents to monitor children's interactions (Juvonen \& Gross, 2008). Because traditional bullying and cyberbullying have their respective processes and cyberbullying is a relatively new phenomenon, the present exploratory study investigated parents' perceptions and awareness of cyberbullying, of the many ways it manifests or extends itself, and its impact on children. 


\section{Chapter 2: A Review of the Literature}

To understand factors affecting parents' perceptions and awareness of cyberbullying, it is important to look at the various components of cyberbullying. While extensive research has been conducted on bullying, the research on cyberbullying lags behind because cyberbullying is a new phenomenon based on modern technology in communication. This chapter reviews the current understanding of cyberbullying, examining how cyberbullying occurs, its current prevalence rates, the media used, and its impact on children and adolescents. However, before getting into cyberbullying, a brief description of bullying is provided to set the framework for the topic of interest: cyberbullying.

\section{Bullying}

Bullying, as defined by Olweus (as cited in Espelage \& Swearer, 2003), is a repeated behavior, including verbal and physical behaviors, that occurs over time in a relationship characterized by an imbalance of strength and power. In addition to physical bullying, other prominent ways of bullying are teasing, calling people names, spreading rumors, and socially ostracizing others (Olweus, 1993). Furthermore, when bullying occurs, there tends to be three roles that people fall into: being a bully, being a victim, or being a bystander (Law et al., 2008). While the bullies tend to be the victimizers and victims are the recipients of the victimization, bystanders play an important role in these interactions. Bystanders hold a great deal of power as they can either give the bully power through watching, not intervening, or being afraid themselves, or they can act to stop the bullying (Law et al., 2008). Bystander effects create difficulties and varied dynamics within peer relationships as a bully's friends may inadvertently give power to him or her by merely being a bystander. Other bystanders may either be afraid for their own safety or may feel helpless or overwhelmed, and they may hurriedly escape the scene. 
Many bullied victims attempt to employ strategies, often suggested by adults, to deal with bullying situations by walking away, telling an adult, or asking the bully to stop (Olweus, 1993).

\section{Prevalence Rates}

Whether students have been bullied has been measured in two ways. Research has looked at whether a student has been bullied during the current school year. Studies of this type show prevalence rates from 30\% to 60\% (Glover, Gough, Johnson \& Cartwright, 2000; Rigby, 2000). Another method for measuring the prevalence rate for bullying is whether a child is bullied frequently, defined as weekly or more. Frequent bullying is estimated to occur from $6 \%$ to $15 \%$ (Rigby, 2000). Other studies go on to estimate bullying to affect $15 \%$ to $20 \%$ of all students in the United States, with verbal teasing and intimidation being the most common forms (Nansel et al., 2003). Thus data, while showing a wide range, still indicate bullying to be a significant problem amongst students in the United States that has traditionally existed in this society for many decades.

\section{Bullying in Minority Populations}

Despite extensive literature on bullying, there has been widespread criticism of its failures in examining bullying amongst members of minority populations. In the limited available research, race and ethnicity have not been found to be significant factors in predicting the frequency or severity of victimization (Nishina et al., 2005; Seals \& Young, 2003). However, some research findings have suggested that African American males are more likely than their other racial and ethnic peers to engage in verbal bullying and name-calling (Peskin et al., 2006). The lack of additional findings and supportive evidence on this topic for minority populations make it difficult to draw conclusions or determine how to best provide multicultural interventions. Peskin et al., (2006) suggest that the lack of findings is because only a handful of 
studies focus on bullying in minority populations. This deficit could be variously interpreted, one being the assumption that interventions are not needed by minority school children.

Another population that is largely neglected in the literature is the bullying of LGBT individuals. The research on the frequency of bullying of LGBT youth is limited though anecdotes, case presentations, journalistic news, autobiographies are replete with narratives of the oppression and marginalization of LGBT youth. Of the limited available literature, Pilkington and D'Augelli (1995) found that 30\% of males and 35\% of females who identify as LGBT were harassed or verbally abused in school because of their sexual orientation. Furthermore, a study conducted by the Human Rights Watch (2001) found that LGBT youth were three times more likely than their peers to have been assaulted at school and four times more likely to have skipped school due to feeling unsafe. The Human Rights Watch (2001) did not provide general rates for bullying. In a more recent study, Swearer, Turner, Givens and Pollack (2008) examined the effects of adolescent males' perceptions of being bullied because of verbal taunts related to gender non-conformity; these authors found that $26 \%$ of males in their study were bullied because others called them gay. The study found that the boys who were bullied because they were called gay suffered from increased verbal and physical bullying as well as psychological distress (Swearer et al., 2008).

\section{Impact of Bullying}

Bullying has many psychological effects on its victims. Being a victim of bullying is related to a variety of problems that range from school avoidance, depression, anxiety, and lower academic functioning (Nakamoto \& Schwartz, 2010) to more severe problems, such as suicides (Olweus, 1993) and school shootings (Leary, Kowalski, Smith, \& Phillips, 2003). Nansel et al. (2003) state that elevated rates of internalizing (e.g., depression) and externalizing (e.g., conduct 
disorder) problems are often found in children who are exposed to bullying, both as victims and as bullies. Most studies only look at the impact on victims, while the prevalence of internalizing and externalizing problems in bullies is an understudied phenomenon (Waasdorp \& Bradshaw, 2011). Furthermore, the long-term prevalence of maladjustment due to bullying is highly dependent on how the individual responds to the bullying (Waasdorp \& Bradshaw, 2011). Using multiple strategies in responding to bullying, such as, bullying back, ignoring the bullying, or telling someone, is seen as prolonging the impact of bullying, but knowledge about which response strategies are most helpful is still an area needing research (Waasdorp \& Bradshaw, 2011).

\section{Cyberbullying}

Cyberbullying has a variety of definitions and manifestations in both the news and in the literature. One common definition of cyberbullying is that it involves the use of information and communication technologies, such as, e-mail, cell phones, smart phones, tablets, pager text messages, instant messaging (IM), defamatory personal Web sites, and defamatory personal polling Web sites, to support deliberate, repeated, and hostile behavior by an individual or group that is intended to harm another person or others (Belsey, 2004; Harcey, 2009). The impact and prevalence of cyberbullying has largely been brought to the attention of the general public through reported incidents in print media, television, and internet news. An example of this is the widely reported and talked about Tyler Clementi cyberbullying incident that occurred in 2010 in Rutgers University (Hu, 2010; Pilkington, 2010).

\section{Reported Incidents of Cyberbullying}

Cyberbullying has appeared in the news on a variety of occasions. Stories have reported on victims from a range of backgrounds and ages, with a number reporting on suicides owing to 
cyberbullying victimization. Discussed here are three of the most prominent news stories on cyberbullying from the years 2003 to 2012. The first, about Ryan Halligan, is one of the earliest reported stories of cyberbullying which lead to a social movement to increase awareness. The second, about Tyler Clementi, is one of the most recent stories that has been in national headlines for two to three years and has greatly increased exposure to cyberbullying. The third, about Megan Meier, reached national as well as international headlines and was the impetus for Missouri passing a law against cyberbullying.

Ryan Halligan. One of the earliest cyberbullying incidents to gain national notoriety is the story of Ryan Halligan from Essex Junction, Vermont. Ryan was a 13-year-old boy who was described as being friendly, warm, and as having a great sense of humor (Halligan, 2010). He also had problems with speech, language, and motor skill development and received special education services from pre-school through the fourth grade (Halligan, 2010). During the fifth grade Ryan had his first bullying experience as kids began to pick on him for his academic and physical difficulties (Halligan, 2010). Because he wasn't being physically hurt, his parents advised him to just ignore the bullies and even got him a therapist to help him learn to cope and build self-esteem (Halligan, 2010). Following this remedy, the bullying stopped but then resurfaced and got worse in the seventh and eighth grades.

During the seventh and eighth grades most of the bullying moved from school to the internet and became cyberbullying. Ryan would get home from school and go on the internet to instant message with friends. While instant messaging with friends and classmates, rumors would spread about him and he would get harassed online and humiliated later at school (Halligan, 2010). In one incident, a 'popular' girl from his class feigned starting a relationship with him through their instant messaging conversations. Ryan learned that she was not serious 
when he approached her at school, and she denied they were together and called him a "loser." She said that "she did not want anything to do with him" (Halligan, 2010). Ryan later learned that this girl and her friends thought it would be funny to make him think that she liked him in order to get him to reveal personal and embarrassing information that she and her friends could spread through the internet and use to harass him (Halligan, 2010). Ryan was getting bullied at school and also when he went home-that was supposed to be a safe place. Due to the hidden internet nature of the bullying, Ryan's parents were unaware that the cyberbullying was taking place. Following these events, Ryan committed suicide and his story has been used nationally in an attempt to educate and raise awareness about cyberbullying and its impact on children (Halligan, 2010). Despite these events, it was not reported if the school took any action against the children who cyberbullied Ryan nor if the school did anything to educate the students and parents about cyberbullying.

Tyler Clementi. One of the most recent cyberbullying incidents to reach national headlines was the experience of Tyler Clementi, a student at Rutgers University in New Jersey. Tyler was an 18-year-old freshman gay student at Rutgers who was a talented violinist and shared his dorm room with another freshman student, Dharun Ravi, who knew that Tyler was gay (Hu, 2010; Pilkington, 2010). In early 2010, Tyler had asked Dharun Ravi for some time alone for himself in their room. Ravi agreed but set up a webcam on his computer which he could access remotely. While Tyler was in their room with another man, Ravi turned on his webcam and reportedly watched, along with at least one fellow student. Ravi watched Tyler's sexual encounter with a man on two separate occasions, again with other invited students (Hu, 2010; Pilkington, 2010). Ravi posted on Twitter Tyler's encounters. His posts included a link that enabled his Twitter followers to stream live video of Tyler's encounter with the man (Hu, 
2010; Pilkington, 2010). Tyler reported this to his resident assistant of his dormitory with the hopes of getting a new room $(\mathrm{Hu}, 2010)$. The next day Tyler committed suicide and posted “Jumping off the gw [George Washington] bridge sorry" on his Facebook wall (Hu, 2010; Pilkington, 2010). Dharu Ravi was convicted of invasion of privacy and several other charges on March 16, 2012. The judge gave him a 10-year prison sentence that Dharu Ravi appealed. Dharu's sentence was reduced to community service because he had already served time in jail while awaiting trial and there was no evidence of criminal or civil charges in his past record. As a result of the Tyler Clementi incident, the New Jersey state legislature enacted the nation's toughest law against bullying and harassment in schools three and a half months after Tyler's death (Perez-Peña, 2011). The law requires schools handle alleged bullying, even after only a single incident, according to newly set rules, and to do so within a strict time frame (Rundquist, 2012). Furthermore, school districts in New Jersey are required to make efforts to stop bullying outside of school grounds, including cyberbullying, if the bullying affects school operations and the rights of other students (Rundquist, 2012).

Megan Meier. Another highly publicized cyberbullying incident is the story of Megan Meier from Dardenne Prairie, Missouri. Megan was a 13-year-old middle school student who loved swimming, boating, dogs, and rap music (Pokin, 2007). She reportedly suffered from Attention Deficit Hyperactivity Disorder, depression, and was cyberbullied by her friend's mother, Lori Drew (Pokin, 2007; Harding, 2008). In the fall of 2006, Megan started the eighth grade at a new school and began to make lots of new friends. She asked her parents if she could create a MySpace account to socialize with friends, and they agreed as long as they held the login password and could monitor her interactions on the website (Harding, 2008;Pokin, 2007). Soon after creating a MySpace account, Megan was messaged by an attractive 16-year-old boy, 
named Josh, who said that he had recently moved to the area and was being homeschooled (Pokin, 2007). Messages were sent back and forth between the two and Megan quickly fell in love with Josh. In mid-October of 2006, however, Josh sent Megan a message stating that he didn't want to be friends with her anymore because he heard that she wasn't very nice to her friends (Pokin, 2007). Following this, Josh continued to send troublesome messages to Megan and shared their private messages with her peers who soon jumped in and created message board posts about Megan, saying "Megan Meier is a slut, Megan Meier is fat" (Harding, 2008; Pokin, 2007). Shortly afterwards Megan hung herself and died the following day, three weeks before her 14th birthday (Harding, 2008; Pokin, 2007).

After a short time it became known that Josh was the product of a fake MySpace account and that a friend's mother, Lori Drew, had created in order to find out what Megan was saying online about her daughter and what Megan felt about her daughter and other people (Harding, 2008; Pokin, 2007). Lori Drew could not be charged in Missouri because there were no state laws under which she could be prosecuted (Pokin, 2007). Lori Drew was eventually indicted and convicted of federal charges of conspiracy and three counts of accessing protected computers without authorization, but she was acquitted on an appeal (Zetter, 2009). The absence of laws protecting against cyberbullying that would have permitted local authorities to prosecute Lori Drew served as an incentive for the passage of a Missouri state law entitled "Megan's Law" as well as other similar state laws (Koman, 2008). These laws aimed to target cyberbullying; however, in May 2012 parts of the Missouri law were struck down by the Missouri Supreme Court that cited concerns over free speech and the law as unconstitutionally broad (Daues, 2012). Prevalence Rates of Cyberbullying

Despite evolving research on cyberbullying, there remain wide discrepancies in the 
reported prevalence rates. A number of studies found that on average $20-40 \%$ of youth report being victimized by a cyberbully (Aricak et al., 2008; Hinduja \& Patchin, 2008; Li 2006; Ybarra \& Mitchell, 2008). On the other hand, Juvonen and Gross (2008) found prevalence rates to be as high as $72 \%$ for $12-17$ year olds who have encountered at least one cyberbullying experience in their life. Tokunaga (2010) stated that Juvonen and Gross (2008) reported such high prevalence rates because the authors substituted the term bullying with the phrase "mean things" that inflated prevalence rates. At the low end of prevalence rates are data from the Youth Internet Safety Survey, a national telephone survey, which found cyberbullying prevalence rates to be at 6.5\% (Tokunaga, 2010; Ybarra, 2004).

Variations in cyberbullying prevalence rates are a problem. Tokunaga (2010) argued that the lack of a common definition for cyberbullying is the cause for variations in findings about prevalence. Bauman (2010) expanded this notion by arguing that much of the research on cyberbullying is difficult to generalize due to methodological as well as definitional differences.

\section{Male versus Female Victims}

Not unlike prevalence rates, research findings on gender differences in cyberbullying victimization are inconsistent (Tokunaga, 2010). However, while a majority of studies indicates that neither gender is victimized more than the other (Juvonen \& Gross, 2008; Patchin \& Hinduja, 2006; Ybarra et al., 2007), some recent studies do suggest that gender is a significant predictor of victimization, with females being victimized at a disproportionately higher rate (Tokunaga, 2010; Ybarra et al., 2007).

Historically, however, research has consistently found that males have been more likely to be bullied than females ( $\mathrm{Li}, 2006)$. Findings of no gender difference and/or females being cyberbullied more than males are contradictory with the traditional bullying literature. Also, 
findings have shown that males are physically victimized significantly more than females, while females are more relationally victimized (Li, 2006). Males are traditionally found to be both bullies and victims of bullying at a much higher rate than females (Boulton \& Underwood, 1992).

Cyberbullying, by nature, is a more relationally aggressive type of a bullying and this may play a role as to why females are on par with males or even higher in this type of bullying behavior (Chibbaro, 2007). Despite this speculation, meta-analyses of cyberbullying research have been unable to draw any relationships between gender and cyberbullying (Tokunaga, 2010).

\section{Role of Age in Cyberbullying}

Age as a significant factor in cyberbullying is very commonly investigated in the literature. Meta-analyses of cyberbullying research show that the largest frequency of cyberbullying occurs in junior high school (Tokunaga, 2010). Williams and Guerra (2007) showed that cyberbullying peaks in middle school and drops off somewhat in high school. This finding about cyberbullying is consistent with conventional bullying, as both appear to be widespread during the middle adolescent developmental period (Bauman, 2010).

However, there is evidence to suggest that cyberbullying is not inversely correlated to age (Tokunaga, 2010). Cyberbullying occurs from elementary school to college to adulthood (Slonje \& Smith, 2007). The highly publicized case of General Petraeus' biographer exemplifies cyberbullying among adults. The biographer sent anonymous, threatening emails to a female friend of the General and his wife. The biographer who developed a sexual relationship with the General became jealous of this other woman (Moore, 2012). This incident exemplifies how adults can become victims of cyberbullying. Even though cyberbullying exists across all age groups, meta-analyses have found significantly more studies on minors under the age of 18 
(Tokunaga, 2010). While taking this information into account, it needs to be remembered that a number of studies found no relationship between age and cyberbullying victimization (Juvonen \& Gross, 2008; Patchin \& Hinduja, 2006; Ybarra, 2004).

\section{Cyberbullying amongst Minority Populations}

Research on cyberbullying has followed the same pattern as traditional bullying research with regards to failing to address diversity issues in their research. Some studies do not report the ethnicity of their participants (Raskauskas \& Stoltz, 2007). Not a single study was found in the literature that primarily investigated cyberbullying experiences of minorities. This is despite the fact that several studies suggest adolescents across all cultures and ethnicities in the United States use the internet and with increased frequency (Berson, Berson, \& Ferrom, 2002; Raacke \& Bonds-Raacke, 2008).

\section{Impact of Cyberbullying}

A review of the literature found that cyberbullying is associated with a range of effects on individuals' lives, from small levels of distress to serious psychological and social problems (Bauman, 2010; Juvonen \& Gross, 2008; Tokunaga, 2010; Ybarra, 2004). The extent of impact on individuals is dependent on the frequency, length, or severity of the cyberbullying (Tokunaga, 2010). While it is assumed that a single event of cyberbullying is far less likely to yield significant psychological problems, the severity of a single event should not be overlooked because it can still cause trauma, such as with Tyler Clementi. The notion of a single-event trauma is not supported in some of the proposed definitions of cyberbullying, where incidents qualify for cyberbullying if only there are repeated occurrences of the phenomenon.

The impact of cyberbullying is measured with respect to different outcomes and by a variety of methods. Some studies look to a decrease in academic performance, as indicated by a 
drop in grades, increases in school absences, and an increase in the perception that school is not safe (Beran \& Li, 2007; Tokunaga, 2010). Decrease in school performance is attributed to poorer concentration and increased frustrations owing to cyberbullying incidents (Patchin \& Hinduja, 2006).

In addition to a decrease in school performance, studies look to psychological problems, such as, mood dysregulation or anxiety (Juvonen \& Gross, 2008; Ybarra, 2004). Depression is often cited as a major result of cyberbullying and is seen as having a pervasive impact on a victim's life (Dehue et al., 2008; Ybarra, 2004). Furthermore, serious levels of stress are noted as an additional result of cyberbullying (Dehue et al., 2008). Juvonen and Gross found that social anxiety was also prevalent among individuals who had been cyberbullied. Social anxiety can also have negative effects in many realms of a child or adolescent victim's life owing to its pervasiveness in social relationships.

\section{How Cyberbullying is Carried Out}

Cyberbullying is carried out through a variety of means, many of which are constantly changing. Dehue et al. (2008) state that Microsoft Service Network (MSN) messenger was the medium most frequently used for cyberbullying, with "placing someone's picture on the internet without permission, hacking, sending MSN bombs or a virus, and anonymous threatening emails" (pp. 218). A variety of websites and other technologies have been used for the purpose of cyberbullying including, but not limited to other messaging services, Facebook, MySpace, YouTube, Twitter, text messaging with cell phones. In instances where cyberbullying is done anonymously, the cyberbully often creates fake accounts to post the material or will block their cell phone number from appearing when they send a text message.

Social media change rapidly and cyberbullying has followed suit. With this in mind, 
MSN messenger has dropped from its status as the most frequently used tool for cyberbullying (Kazeniac, 2009; Protalinksi, 2012). The early rise and fall in the popularity of MySpace mirror the rise and fall of cyberbullying through that website. More popular media like Facebook, currently the most visited website in the United States (Protalinksi, 2012), is more likely to be used for cyberbullying today than it was only a few years ago. Of note, and as seen in the film The Social Network, the founder of Facebook, Mark Zuckerberg, started his website by calling for the evaluation of the bodies of his women peers at Harvard College, a type of cyberbullying that resulted in a huge negative response from Harvard college students (Rudin \& Fincher, 2010). Different media afford different ways in which cyberbullying can occur. For example, YouTube can be used to post videos of peers doing embarrassing things that are available to the public, whereas text messaging can be used to threaten, harass, or make fun of an individual in a private manner. Some media offer more anonymity to cyberbullies than others because of the ability to create fake user accounts. The cyberbullying of Megan Meier occurred in this way through the creation and use of a fake MySpace account.

\section{Information about Social Media}

Social media is compromised of technology that allows for the creation and exchange of user-generated content, ranging from real time messaging to posting content on web pages (Kaplan \& Haenlein, 2010). These technologies can include blogs, social networking websites, content sharing websites, instant messaging, and a rapidly growing number of other technologies (Kaplan \& Haenlein, 2010). The following social media technologies are the ones most commonly used for the purpose of cyberbullying.

Facebook. Facebook is a social networking service that was launched in 2004 and has since grown to over 845 million users worldwide with projections to have 1 billion users by 
August 2012 (Protalinksi, 2012). Use of Facebook includes making a personal profile, listing interests and contact information, adding other users as "friends," writing messages to other users and posting information, such as pictures and status updates on one's personal profile. Facebook allows anyone over the age of 13 to register and create a profile for the website (Facebook, 2012). However, it is reported that at least 7.5 million children under the age of 13 have registered and use Facebook (Consumer Reports, 2011).

Facebook does not actively monitor for cyberbullying. However, users can report it to the website. Reporting is confidential and Facebook reviews the material to decide whether or not it should be removed. Facebook speaks about bullying in the "Safety" section of its website. Facebook (2012) states:

If you ever receive hurtful or abusive messages or posts on your profile page you have options. Depending on how serious the situation is, you can ignore it, ask the person to stop, unfriend or block the person, or tell your parents, a teacher, a counselor, or another adult you trust. Everyone deserves to be treated with respect. ("Playing it safe," para. 6) Facebook (2012) expands upon this stance in its Community Standards where it states:

Facebook does not tolerate bullying or harassment. We allow users to speak freely on matters and people of public interest, but take action on all reports of abusive behavior directed at private individuals. Repeatedly targeting other users with unwanted friend requests or messages is a form of harassment. (Community Standards, para. 3)

YouTube. YouTube is a video sharing website that was founded in 2005 and is user driven. Users upload videos and other content to the website for others to view. In addition to posting videos, users can also leave comments on videos posted by others. While demographic data about YouTube users is not available, it is known that over 4 billion videos are viewed on 
YouTube every day (Oreskovic, 2012). YouTube has community policies in an effort to reduce abuse of the website, which include prohibiting users from posting material that is sexually explicit, materials against copyright laws, hate speech, spam, and predatory behavior (YouTube Community Guidelines, 2012). Violations of these may result in being banned from the website, but there is no indication of other steps that would be taken if YouTube policies were violated (YouTube Community Guidelines, 2012).

YouTube has a safety center on their website with a section devoted to cyberbullying and harassment. It explains to users what cyberbullying is and offers suggestions on how to stop it. YouTube suggests that in order to stop cyberbullying, an individual should block problem users, control the comments posted on his/her channel (a personal page with a user's videos), turn video comments off, and delete and block a user from commenting on videos you own (YouTube Safety Center, 2012). YouTube goes on to state that "Sometimes criticism and insults can escalate into more serious forms of harassment and cyberbullying. If specific threats are made against you and you feel unsafe, tell a trusted adult, or report to your local law enforcement" (para. 3).

YouTube provides users with a Help and Safety Tool, which is information from the National Crime Prevention Council and also offers the ability to flag cyberbullying videos for review by the YouTube team (YouTube Safety Center, 2012).

MySpace. MySpace is a social networking website that was the most visited social network from 2005 until early 2008, when it was surpassed by Facebook in April 2008 (Techtree, 2008). Since then the number of MySpace users has declined steadily, plummeting to 33.1 million users in August 2011 (Steel, 2011). MySpace users have profiles that can be personalized and allows users to add friends, post pictures, add biographical information, and 
other information. MySpace uses “bulletins” which are posts that a person's MySpace friends can see and also has a place to leave comments for all viewers to read. It also includes an instant messenger called MySpaceIM and a video sharing website called MySpace TV. MySpace allows users as young as 13 to create a profile, and users 13- to 15-years-old have profiles that are automatically made "private" (MySpace Terms of Use, 2012). A private account only allows users' friends to access their account. In an effort to promote safety, MySpace does not allow users over the age of 18 to add users from 13- to 15-years old unless the 18-year-old user knows the name and/or email address of the younger user (MySpace terms of use, 2012).

According to MySpace, the website carefully reviews each profile for inappropriate content. If MySpace finds any content that violates their Terms and Conditions, which includes cyberbullying and harassment, they delete the content (MySpace reporting content, 2012). MySpace explicitly states that any content they review deemed to be cyberbullying will be removed, and that users can also report abusive content to be reviewed (MySpace reporting content, 2012).

Instant messaging services. Instant messaging, also known as online chatting, is a text based conversation between two or more individuals in real time over the internet or a network. Internet based instant messaging rapidly gained popularity in the mid 1990s with services such as ICQ and AOL Instant Messenger (Kelly, 2010). Soon thereafter, other companies developed their own instant messaging services such as MSN Messenger and Yahoo Messenger (Kelly, 2010). Today, social networking websites and some email servers, namely Gmail and Yahoo, offer instant messaging services. Other companies also offer instant messaging, such as Skype, which allows for live video chat in addition to text based communication. Instant messaging services have remained very popular with services like MSN Messenger having 330 million 
active users and Skype having 521 million total users (Crum, 2011).

Individuals typically choose a username or "screen name" with which they can be contacted for chatting. This username can vary from the individual's email address to being a randomly computer generated name. Users communicate through knowing or keeping a list of the usernames of their friends as this facilitates communication. Usernames, while typically used to identify an individual, can also create anonymity due to the ease of creating one and the inability to know who the actual user is on the other end of the conversation. Conversations on instant messaging platforms are not moderated; however, abuse of their terms of service could lead to the platform deleting the offender's account (Skype terms of use, 2012; Windows code of conduct, 2012)

Twitter. Twitter is an online social networking service that allows its users to send "tweets," or posts that are up to 140 characters in length, and read "tweets" posted by others. Tweets are visible to the public and are typically seen by people who subscribe to follow the tweets of particular users. As of 2011, Twitter had over 300 million users and with its users producing over 300 million tweets a day (Taylor, 2011). In January 2009, Twitter moved up to the third highest ranking social networking site on the internet (Kazeniac, 2009). The majority of twitter users are adults as only 11 percent of Twitter's users are aged 12 to 17 , and there are also slightly more female users than male users at a usage rate of 53 percent for women (Miller, 2009; Cheng \& Evans, 2009).

Twitter does not moderate tweets and will only remove an account if it violates their policies - violations, such as impersonation of another person or direct threats of violence (Twitter rules, 2012). Twitter also has a safety center on their website that dedicates a section to teen safety. Twitter talks about "negative and hurtful interactions" between people online and 
offers advice on how to handle these situations (Twitter safety tips for teens, 2012). They suggest talking to someone with authority or accessing online resources they provide that include websites and twitter users dedicated to stop bullying (Twitter safety tips for teens, 2012).

\section{Common Strengths and Weaknesses of Social Media}

Social media have a variety of strengths and weaknesses, which parents should critically evaluate before permitting their children to subscribe to social media. The most common strength of social media is the ability for its users to connect and share information, ideas, creativity and more. This communication is not only instantaneous, but can also be broadcast to a large group of people at the same time. The benefits of this communication are profound and can greatly enrich an individual's social interactions and the way an individual consumes information (e.g., about entertainment, political events, etc.) The ease with which people can interact with one another and their greater communities through social media is unrivaled.

There are several weaknesses also. One weakness is the phenomenon of being constantly connected to others, which means that it can be difficult for people to 'disconnect' or get away from social media interactions. In the case of cyberbullying, it means that victims can be contacted and cyberbullied 24 hours a day. Furthermore, social media takes place in the public domain which means that many interactions between individuals is often not private. Posts on Facebook, YouTube, MySpace, and Twitter can be seen by a large audience and can create an easy forum for someone to be publicly cyberbullied. Additionally, many of an individual's posts are preserved well after they are posted; and embarrassing or less than desirable posts have little way of disappearing. Some posts may even go "viral," meaning they could easily be shared and viewed by thousands or even millions of people. Parents must weigh the benefits of social media with the weaknesses so that they can critically evaluate social media and make informed 
decisions for their own family about its use.

\section{Parental Perceptions of Cyberbullying}

Research on adult perceptions and awareness of cyberbullying is relatively sparse.

Dehue, Bolman and Völlink (2008) study on youngsters' experiences and parental perceptions of cyberbullying was the only one the author found that gave attention to parental perceptions. This study surveyed 1,211 students in the Netherlands and invited their parents to participate as well. Of the participating students, responses from 831 parents were collected and analyzed. The author did not provide any sociodemographic information about the students or their parents. The study found that more than half of parents set rules for their children about what they could do on the internet and how often they could use it (Dehue et al., 2008). Even though a majority of parents were found to set rules about their children's use of the internet, many of them were unaware of the cyberbullying that was occurring (Dehue et al., 2008). The percentage of parents who reported that their child was being cyberbullied (11.8\%) was significantly lower than the percentage of students who reported being cyberbullied (22.9\%) (Dehue et al., 2008).

Furthermore, the study found a discrepancy between parent and student reports of engagement in cyberbullying behaviors. The number of students that reported engaging in cyberbullying behaviors $(17.3 \%)$ was far more than the number of parents that reported that their child engaged in cyberbullying behaviors (4.8\%; Dehue et al., 2008). The authors did not provide tables or additional information on parents as they did for the students and no explanation is given for the omission.

Popular literature has begun to look at parental perceptions of cyberbullying. The website Digital Journal conducted a survey to investigate what parents thought about cyberbullying. They found that "almost one in three parents who have children aged between 12-17 thought that 
cyberbullying was more worrying than domestic terrorism, car accidents and suicide" (Fazackarley, 2010). Furthermore, the New York Times wrote about parents having to play catch-up in a new digital world of bullying. According to the New York Times article, parents feel that they have to become more technologically savvy in order to begin to learn how they can help their children (Hoffman, 2010). Many parents have turned to community lectures by psychologists, technology experts, and police in order to educate themselves on the basics of technology and cyberbullying (Hoffman, 2010). Parents are becoming more aware of cyberbullying and its impacts through both media reports and hearing about it from their own children. Popular literature suggests that as parents become aware of cyberbullying, they will subsequently become aware of how little they know about communication technology and how cyberbullying occurs (Hoffman, 2010). Popular literature appears to be talking about parental reactions and perceptions of cyberbullying at a much greater rate than that of the research or professional literature.

School personnel's perception of cyberbullying. In addition to parents, few school professionals have been found to be aware of cyberbullying among students (Beran \& Li, 2005). Slovak and Singer (2011) attempted to look further into the perceptions of professionals at schools with regards to cyberbullying. They found that while school social workers were aware of the impact that cyberbullying could have on students, they were also ambivalent about their ability to intervene and were unfamiliar with the different technologies that could be used for cyberbullying (Slovak \& Singer, 2011). This is consistent with Blair's (2003) assertion that school administrators are confused about their legal role and jurisdiction when attempting to address cyberbullying.

Confusion about schools' roles in addressing cyberbullying has a direct impact on the 
creation and implementation of policies that could aid school personnel in monitoring and controlling cyberbullying (Slovak \& Singer, 2011), as well as on their communication with parents about cyberbullying among their students. It maybe that various social media do a better job in educating users of options in dealing with cyberbullying and in moderating cyberbullying posts than do schools. Schools have implemented bullying prevention projects in classrooms and through guidance offices (Espelage et al., 2013). One wonders if schools will do similar interventions for cyberbullying and whether it is even feasible for schools to do so because cyberbullying is less visible to the public than the school yard physical bullying.

\section{Summary}

Research on bullying and cyberbullying are reviewed in this chapter. There are a number of different mediums where cyberbullying takes place, and these are constantly changing and expanding as internet and electronic technologies advance. Furthermore, there is great variability between websites regarding whether or not they monitor content and what they do with content that is violent or abusive. Constant changes in the mediums of cyberbullying, as well as variability in the policies of websites, make it difficult for parents to keep up with all of the innovative ways through which their children are interacting with each other. While innovations in social media have a positive impact on society in various ways, including ease of sharing information and virtually connecting with others, they are also used in harmful ways, as in the case of cyberbullying. Various examples of cyberbullying have been given in this chapter, including the cases of Megan Meier and Tyler Clementi, which help to elucidate the traumatic impact of cyberbullying on adolescents. Specific social media websites have been described that can host cyberbullying. Research on parental perception and awareness of cyberbullying has been given a brief review because of a dearth of professional literature on this topic. 


\section{Conclusion}

In addition to providing a review of the literature surrounding cyberbullying, this chapter has expanded upon the various outlets and effects of cyberbullying. The next chapter, Chapter 3, describes the methodology used to conduct the study proposed in Chapter 1. Chapter 3 informs about participants, instrumentation, procedures, research hypotheses, and data analyses of the study. 


\section{Chapter 3: Method}

The author examined caregivers' (parents, guardians, and grandparents) perceptions and awareness of cyberbullying of school-going children. Participants filled out two surveys: (a) a demographic questionnaire and (b) the parents' cyberbullying perception and awareness measure designed by the author. Due to limited research on parental and other caretakers' awareness of cyberbullying, the study was limited to examining the relationships among participants' cyberbullying perceptions and demographic characteristics. In this chapter, readers learn about the study's participants, measures, procedures, ethical concerns, research hypotheses, research design, and data analyses.

\section{Participants}

There were 99 participants (76.8 \% female, 23.2\% male), and they self-reported that they were the primary caregivers for their children. Of these, $91.9 \%$ were parents, $4.0 \%$ were grandparents, and 4.0\% were other primary caregivers. Forty-two $(42.4 \%)$ reported having 2 children, $24(24.2 \%)$ reported 3 children, $15(15.2 \%)$ reported 1 child, $13(13.1 \%)$ reported 4 children, 4 (4.0\%) reported 6 children, and $1(1.0 \%)$ reported having 5 children. Of these, 46 (46.5\%) caregivers reported having at least 1 child between 1 st and 4 th grade, $45(45.5 \%)$ reported having at least 1 child between 5th and 8th grade, $37(37.4 \%)$ reported having at least 1 child between 9th and 12th grade, and $32(32.3 \%)$ reported having at least 1 child between 1 st year and 4th year of undergraduate college.

The majority of participants $(n=56,56.6 \%)$ identified living in small towns. Twenty respondents $(20.2 \%)$ identified living in small cities, $12(12.1 \%)$ identified living in large metropolitan cities, and $11(11.1 \%)$ identified living in rural areas. More respondents reported living in New Hampshire $(n=35,35.4 \%)$ than any other state. Massachusetts was the second 
most represented state with 34 respondents (34.3\%). The participants could be described as essentially a New England sample. Table 1 lists the 13 states from which the participants came. 
Table 1

Participants who live in the United States by State

\begin{tabular}{lcc}
\hline \multicolumn{1}{c}{ State } & $N$ & Valid \% \\
\hline New Hampshire & 35 & 35.4 \\
Massachusetts & 34 & 34.3 \\
Connecticut & 12 & 12.1 \\
California & 4 & 4.0 \\
New York & 3 & 3.0 \\
Florida & 2 & 2.0 \\
Arizona & 1 & 1.0 \\
Colorado & 1 & 1.0 \\
Illinois & 1 & 1.0 \\
Maine & 1 & 1.0 \\
Nevada & 1 & 1.0 \\
North Carolina & 1 & 1.0 \\
Vermont & 1 & 1.0 \\
\hline
\end{tabular}

Ten individuals (10.1\%) reported being between 22-32 years of age, 31 individuals $(31.3 \%)$ reported between $33-43$ years of age, 49 individuals (49.5\%) reported between $44-54$ years of age, and 9 individuals $(9.1 \%)$ reported being between 55-65 years old. The vast majority of caregivers, $n=77(77.8 \%)$, reported that they were married. Table 2 lists the participants' marital statuses. The vast majority of participants, $n=90(90.9 \%)$, reported that they identify as White/Caucasian. Table 3 lists participants's self-identified race or ethnicity. 
Table 2

Marital Status

\begin{tabular}{lcc}
\hline Marital Status & $N$ & Valid \% \\
\hline Married & 77 & 77.8 \\
Divorced & 11 & 11.1 \\
In a relationship (not married) & 5 & 5.1 \\
Single & 3 & 3.0 \\
Separated & 2 & 2.0 \\
Widowed & 1 & 1.0 \\
\hline
\end{tabular}


Table 3

Participants' Race or Ethnicity

\begin{tabular}{lcc}
\hline \multicolumn{1}{c}{ Ethnicity } & $N$ & Valid \% \\
\hline Caucasian/White American & 90 & 90.9 \\
African American & 3 & 3.0 \\
Latino/Hispanic & 3 & 3.0 \\
Biracial/Multiracial & 2 & 2.0 \\
Asian American & 1 & 1.0 \\
\hline
\end{tabular}

Participants with a bachelor's degree $(n=35,35.4 \%)$ were the most represented in the sample, followed by 20 participants with a master's degree $(20.2 \%), 18$ with some college (18.2\%), 15 with an associate's degree (15.2\%), 7 with a high school or GED diploma (7.1\%), and 3 with a doctoral degree (3.0\%). Participants were also asked about their class and income. More participants identified as being middle class (39.4\%) than any other group. Working class with middle to high income (25.3\%) was the second most represented group. Table 4 shows participants' class and income. The sample may be described as White, middle class, college educated, and married. 
Table 4

Class and Income

\begin{tabular}{lcc}
\hline \multicolumn{1}{c}{ Class and Income } & $N$ & Valid \% \\
\hline Middle Class & 39 & 39.4 \\
Working Class, Middle to & 25 & 25.3 \\
High Income & & \\
Upper Middle Class & 19 & 19.2 \\
Working Class, Poor & 5 & 5.1 \\
Very Rich, Million dollars and & 4 & 4.0 \\
above & & \\
Unemployed/Part time & 4 & 4.0 \\
Rich 500k & 3 & 3.0 \\
\hline
\end{tabular}

\section{Instrument}

The literature review on cyberbullying informed the author's survey questions. The survey is called Parents' Perception and Awareness of Cyberbullying (PPAC). The quantitative section of the PPAC consisted of 29 items and used a Likert-type scale of Strongly Disagree (1), Disagree (2), Agree (3), and Strongly Agree (4). The quantitative section consisted of 8 items. See Appendix B for the PPAC survey. PPAC's first page carried the informed consent form (see Appendix C). The second page obtained demographic information (Appendix A), which was comprised of multiple choice responses. The survey was expected to take 15-20 minutes to complete and was written at the 8 th grade reading level. The internal consistency reliability for the full PPAC scale was $\alpha=.81$.

PPAC explored what perceptions parents have about cyberbullying and their awareness of cyberbullying's impact on youth. Item contents were informed by Slovak and Singer's (2011) study that looked at school social workers' perceptions of cyberbullying; and by Dehue et al's 
(2008) study that looked at both youngsters' experiences and parental perceptions of cyberbullying. Specifically, PPAC gathered information about (a) parents' beliefs about the severity of cyberbullying, (b) perceptions of the impact of cyberbullying on their children, (c) familiarity with cyberbullying mediums, (d) acquisition of knowledge and understanding about cyberbullying, and (e) beliefs about preventative measures to intervene with cyberbullying.

PPAC was exploratory and included quantitative items and a few short open-ended questions. The PPAC was separated into 6 subsets of items, which are presented below. Eight open-ended questions gathered personal statements. Both quantitative and qualitative data were useful for an exploratory study because they helped to increase breadth and depth of understanding of a relatively new topic. Mixed methods allow researchers to expand on participant responses on a scaled measure and to benefit from the strengths inherent in both methods.

Parents' beliefs about extent of cyberbullying. In order to identify if parents believed cyberbullying is a problem that should be addressed, the following survey questions were asked. The higher the score, the more severe the parent believed was the extent of cyberbullying. The internal consistency reliability of parents' beliefs about extent of cyberbullying was $\alpha=.16$, a low reliability coefficient indicating low trends in the responses of the sample.

2. Cyberbullying is a problem at my child's school. (Q2)

3. Cyberbullying occurs during school time. (Q3)

4. Cyberbullying occurs outside of school. (Q4)

5. Cyberbullying is an issue that needs increased attention from parents. (Q5)

10. I do not know whether cyberbullying is addressed at my child's/children's school. (reverse item) (Q10) 
Perceptions of impact of cyberbullying. In order to explore if parents perceived cyberbullying to have a greater negative impact on their children's lives than traditional bullying, the following survey questions were asked. The internal consistency reliability of perceptions of impact of cyberbullying was $\alpha=.39$, which was a low reliability coefficient indicating low trends in the responses of the sample.

7. Cyberbullying is more harmful than traditional bullying (i.e., in the schoolyard and hallways). (Q7)

9. My child is as likely to talk to me about cyberbullying as he/she is to talk to me about 'traditional' bullying (Q9). (reverse item)

11. I believe that cyberbullying can cause or has caused psychological harm to my child/children. (Q11)

12. Cyberbullying occurs less frequently than bullying in my child's/children's schoolyard and hallways. (reverse item) (Q12)

13. I have heard or read that cyberbullying has contributed to suicide among students. (Q13)

Family practices regarding the internet. In order to explore family practices in monitoring children's internet use and/or restricting their use of the internet, the respondents were asked to answer the following questions, in addition to two open-ended questions at the end of the survey. The internal consistency reliability of family practices regarding the internet was $\alpha$ $=.74$, which was an acceptable reliability coefficient and might be even considered strong, given that there were only two items.

14. I believe it is important to monitor my child's use of the internet. (Q14)

16. I believe it is important to place restrictions on my child's/children's use of the internet. (Q16) 
Familiarity with cyberbullying mediums. To understand parents' familiarity with and ability to identify mediums used for cyberbullying, the respondents were asked to answer the following survey questions, in addition to an open-ended question at the end of the survey. The internal consistency reliability of familiarity with cyberbullying mediums was $\alpha=.81$, which was a strong reliability coefficient.

19. I am familiar with Facebook. (Q19)

20. I am familiar with MySpace. (Q20)

21. I am familiar with instant messaging services. (e.g., MSN messenger) (Q21)

22. I am familiar with Twitter. (Q22)

23. I am familiar with YouTube. (Q23)

24. I am familiar with text messaging. (Q24)

Acquisition of knowledge about cyberbullying. To understand how parents learned about cyberbullying, and, specifically, if they learned about it more from the media, the following survey questions were asked along with an open ended question at the end of the survey. The internal consistency reliability of acquisition of knowledge about cyberbullying was $\alpha=.37$, a low reliability coefficient, suggesting low trends in the responses of the sample.

25. I have not learned about cyberbullying from the news on radio or television. (reverse item). (Q25)

26. My child's/children's school has informed me about cyberbullying. (Q26)

27. I have learned about cyberbullying from my child/children. (Q27)

28. I have done my own research/investigation about cyberbullying. (Q28)

Beliefs about preventative measures. To understand what parents believe to be helpful preventative measures that can mitigate the prevalence of cyberbullying, the following survey 
questions were asked along with an open-ended question at the end of the survey. The internal consistency reliability of beliefs about preventative measures was $\alpha=.74$, which was an acceptable reliability coefficient.

31. Laws or school policies currently in place address cyberbullying adequately. (Q31)

32. Schools should be proactive in addressing cyberbullying. (Q32)

33. Schools' increased involvement in addressing cyberbullying would not significantly reduce cyberbullying. (Q33)

34. Parents should be more proactive in addressing cyberbullying with their child/children (whether their child is a victim or a cyberbully). (Q34)

35. Parents' involvement in addressing cyberbullying would not reduce their child/children's cyberbullying, whether as a victim or as a cyberbully. (reverse item) (Q35)

36. More laws should be passed to prevent or punish cyberbullying. (Q36)

\section{Open-ended questions.}

Throughout the PPAC, there were 8 open-ended questions, which are given below.

1. What does cyberbullying mean for you? (Q1)

6. How do you see cyberbullying as a problem? (Q6)

15. Please list the different ways, if any, you monitor your child's use of the internet. (Q15)

17. Please list the different restrictions, if any, you place on your child's/children's use of the internet. (Q17)

18. Please note in the lines below the different types of media through which cyberbullying occurs (i.e., specific websites, devices used for messaging, etc.). (Q18) 
29. Please list any other ways through which you have learned about cyberbullying. (Q29)

30. When a youth is cyberbullied, what do you believe are some obstacles for him/her for getting help? (Q30)

37. Please list any additional ways you think that cyberbullying could be better addressed. (Q37)

\section{Procedures}

Participants were invited by an announcement on social networking sites_Facebook and Twitter — and various professional listservs, including divisions of the American Psychological Association (APA) and the California Psychological Association (CPA). APA divisions included APA Division 37 (Society for Child and Family Policy and Practice), APA Division 46 (Society for Media Psychology and Technology), and CPA Division VI (Media Technology and Communication).

The internet announcement directed participants to the website link of https://www.psychdata.com/s.asp?SID=154355, where the PPAC was posted. An introductory letter presented the informed consent form (Appendix C), and participants were told that by answering the survey, they indicated consent. Participants were not asked to sign or, otherwise, identify themselves in any way. IP account numbers were not collected. Any responses via other means, email for example, were deleted and not included in the study.

Participants indicated their agreement to participate by clicking a button, acknowledging that they had read and agreed with the procedures of the study. Then, they completed the PPAC online survey and questions on demographics. After completing the survey, participants submitted it to Psychdata.com. These responses were then entered into SPSS for data analysis. 
Ethical research practice. Prior to the study's commencement, a review of measures, procedures for data collection, steps taken for the protection of human participants, such as their confidentiality and anonymity, and their rights was completed by the Antioch University Institutional Review Board (IRB). All phases of the study were carried out in compliance with Antioch's IRB requirements and the APA Code of Ethics (APA, 2002/2010) for research with human participants.

\section{Research Hypotheses}

There are five research hypotheses that were addressed by the study:

1) A majority of parents believe that cyberbullying is a problem that should be better addressed.

2) A majority of parents perceive children's experiences of cyberbullying to have less of a negative impact on their children than traditional bullying.

3) Younger parents are more likely to identify and be familiar with mediums for conducting cyberbullying than older parents.

4) Parents are more likely to have learned about cyberbullying from television than any other media.

5) Parents perceive greater school involvement (micro-level) and the passage of new laws (macro-level) to be the most helpful preventative measures that can mitigate the prevalence of cyberbullying.

\section{Data Analysis}

The analysis first looked at descriptive statistics, including means, standard deviations, frequencies, percentages, and score distributions. Psychometric properties of the quantitative section of the survey, such as Cronbach's alpha (reported in the Instrument section of this 
chapter), and item-total score correlations were investigated. In addition, select demographic variables (e.g., age, sex, education, geographic location) were examined in relationship to the PPAC's dimensions.

The following analyses were performed for the study's research hypotheses:

Hypothesis 1. A majority of parents believe that cyberbullying is a problem that should be better addressed. This hypothesis was verified through score frequency distributions, means, and standard deviations. Majority was defined as 50\% and more.

Hypothesis 2. A majority of parents perceive children's experiences of cyberbullying to have less of a negative impact on their children than traditional bullying. A t-test was performed where the independent variable was "Traditional Bullying”/“Cyberbullying” to test whether the mean score for each type of bullying was same or different.

Hypothesis 3. Younger parents are more likely to identify and be familiar with mediums for conducting cyberbullying than older parents. Two independent sample groups were formed, "Young Parents" and "Older Parents" to test whether their mean scores were same or different. These two independent sample groups were formed by dividing the sample's age demographics in half. Participants were eligible to take part in the study if they were between the ages of 22 and 65; therefore, the young parents' group included caregivers between 22- and 43-years-old and older parents' age group included caregivers between 44- and 65-years-old.

Hypothesis 4. Parents are more likely to have learned about cyberbullying from television than any other media. The independent variable was Television/Other Media. A t-test verified whether the mean score for obtaining information on cyberbullying was the same or different for the two types of information resources. 
Hypothesis 5. Parents perceive greater school involvement (micro-level) and the passage of new laws (macro-level) to be the most helpful preventative measures that can mitigate the prevalence of cyberbullying. An ANOVA was performed, where the independent variable consisted of various ecological systemic levels, and the dependent variable was the rating of preventative measures.

Results from t-tests and an ANOVA provided effect sizes as well as accounted for respective variances in parents' perceptions and awareness.

\section{Qualitative Data Analysis}

Thematic analysis was used to develop themes that occurred in the open ended survey questions. Braun and Clarke (2006) outlined the six phases of thematic analysis, which were used to develop the themes in the study. These phases are "phase 1: familiarizing yourself with your data" (Braun \& Clarke, 2006, p. 87), “phase 2: generating initial codes” (Braun \& Clarke, 2006, p. 88), “phase 3: searching for themes" (Braun \& Clarke, 2006, p. 89), "phase 4: reviewing themes" (Braun \& Clarke, 2006, p. 91), "phase 5: defining and naming themes" (Braun \& Clarke, 2006, p. 92), and "phase 6: producing the report" (Braun \& Clarke, 2006, p. 93).

Phase 1, familiarizing yourself with the data, was completed by thoroughly reading over the qualitative responses to each question in the survey. This was followed by the completion of phase 2, generating initial codes. After becoming familiarized with the responses, it became possible to identify the pertinent content in the responses and develop codes to help organize and group the data together. These codes were then organized and combined to create themes in the data for each of the open ended questions. The creation of themes completed the end of phase 3 for thematic analysis. Phase 4 consisted of reviewing themes, and this included determining if there was enough data to support each created theme. Each theme was reviewed in the context of 
the responses supporting it and the decision was made to either remove it or keep it. If responses were not congruent with themes, it was also investigated if they better fit with another theme that was kept. Phase 5 was conducted through creating narratives for the proposed themes. Depth and meaning were given to the themes through creating narratives, and using excerpts from the responses helped to accomplish this. This is shown in the results section for qualitative data. The sixth and final phase, producing the report, was completed to support the presence of each theme. The frequency of the themes was calculated, followed by the percentage of data supporting the themes in relation to the overall total of the themes. These themes were then listed in tables with the most frequently occurring themes appearing first, and the least frequently appearing themes occurring at the bottom of the table.

\section{Conclusion}

The study was exploratory in nature and used a survey method consisting of quantitative and qualitative open-ended items developed by the author. Although research on cyberbullying and its impact on child and adolescent victims are starting to increase (e.g., Cyberbullying Research Center, 2012; Diamanduros et al., 2008; Ybarra et al., 2007), research on parental perceptions and awareness of the phenomena is still in its early stages. Given the exploratory nature of the study that used a mixed methods design, several analyses were performed so that future studies might have the opportunity to focus on only a few results from the present study and utilize sophisticated statistical models, including experimental designs with control groups, as well as in-depth individual interviews with parents who score at the high and low ends of the PPAC measure. 


\section{Chapter 4: Results}

The purpose of the study was to assess caregivers' perceptions and awareness of cyberbullying. Both quantitative and qualitative data were examined to gain a comprehensive understanding of caregivers' perceptions and awareness of the topic under study. Participants were recruited through online announcements.

\section{Quantitative Data}

\section{Internal Consistency Reliability}

Cronbach's alpha was calculated to evaluate the reliability of the PPAC and its proposed 6 dimensions. Each item of the measure was evaluated to determine if deletion of certain items would significantly improve the measure's Cronbach's alpha. Items 1 and 2 were deleted after determining that their removal would significantly improve the full measure's Cronbach's alpha. The Cronbach's alpha for the full PPAC measure is $\alpha=81$. The Cronbach's alpha for each

dimension is given in Table 5. It is recognized that three dimensions, Belief, Impact, and Knowledge, had low reliabilities. 
Table 5

Reliability of Six Dimensions

\begin{tabular}{lc}
\hline \multicolumn{1}{c}{ Dimension } & Cronbach's Alpha \\
\hline Belief & .16 \\
Impact & .39 \\
Internet Practices & .74 \\
Familiarity & .81 \\
Knowledge & .37 \\
Prevention & .74 \\
Full Cyberbullying Scale & .81 \\
\hline
\end{tabular}

Note: Belief is parents' beliefs about extent of cyberbullying; Impact is perceptions of impact of cyberbullying; Internet Practices is family practices regarding the internet; Familiarity is familiarity with cyberbullying mediums; Knowledge is acquisition of knowledge about cyberbullying; and Prevention is beliefs about preventative measures.

\section{Tests of Major Hypotheses}

Table 6 shows the means and standard deviations for participants on all the 6 dimensions as well as the full PPAC scale. The absolute minimum and maximum scores for each dimension are as follows: Belief about Extent , 5-20; Impact, 5-20; Internet Practices, 2-8; Familiarity, 6-24; Knowledge, 4-16 ; and Prevention, 6-24. What is shown as the mean in Table 6 is based on the Likert-type scale of 1 = Strongly Disagree, $2=$ Disagree, $3=$ Agree, and $4=$ Strongly Agree. On average the parents agreed that cyberbullying is a problem, but they were not strongly concerned. 
Table 6

Cyberbullying Subscale Means and Standard Deviations

\begin{tabular}{lcc}
\hline \multicolumn{1}{c}{ Measure } & Mean & $S D$ \\
\hline Belief about Extent & 2.88 & .44 \\
Impact & 3.09 & .38 \\
Internet Practices & 3.40 & .61 \\
Familiarity & 3.20 & .49 \\
Knowledge & 2.75 & .52 \\
Prevention & 3.19 & .41 \\
Full PPAC Scale & 3.03 & .27 \\
\hline
\end{tabular}

Note: Belief is parents' beliefs about severity of cyberbullying; Impact is perceptions of impact of cyberbullying; Internet Practices is family practices regarding the internet; Familiarity is familiarity with cyberbullying mediums; Knowledge is acquisition of knowledge about cyberbullying; and Prevention is beliefs about preventative measures.

Hypothesis 1. A majority of parents believe that cyberbullying is a problem that should be better addressed. In Table 7, the Belief about Extent dimension is split into two score groups. Participants, who scored higher than 2.5 , suggesting that they agreed that cyberbullying is a problem that needs to be addressed, were placed in one group. Participants who scored lower than 2.5 , suggesting that they disagreed that cyberbullying is a problem that needs to be addressed, were placed in another group. It was found that a majority of caregivers $(n=78$; $83.8 \%$ ) believed that cyberbullying is a problem that should be better addressed. Hypothesis 1 was retained. 
Table 7

Beliefs About Extent of Cyberbullying

\begin{tabular}{lcc}
\hline \multicolumn{1}{c}{ Group } & $\mathrm{n}$ & Percentage \\
\hline $\begin{array}{l}\text { Cyberbullying is a problem } \\
\text { that needs to be addressed }\end{array}$ & 78 & $83.8 \%$ \\
Cyberbullying is not a & 15 & $16.2 \%$ \\
problem that needs to be & & \\
addressed & & \\
\hline
\end{tabular}

Hypothesis 2. A majority of parents perceive children's experiences of cyberbullying to have less of a negative impact on their children then traditional bullying. Caregivers perceived traditional bullying to have a significantly more negative impact on the lives of children than cyberbullying $t(90)=-9.48, p<.001, d=.98$, a large effect size. Hypothesis 2 was retained.

Table 8 shows the means and standard deviations for caregivers' beliefs about the Extent and Impact of both cyberbullying and traditional bullying. Caregivers were found to perceive children's experiences of cyberbullying to be less extensive than traditional bullying, $t(90)=$ $-2.24, p=.03, d=.22$, a medium effect size. A hypothesis to this effect (i.e., Extent of cyberbullying) was not made, but a t-test was performed upon viewing the Extent means for traditional bullying and cyberbullying. 
Table 8

Beliefs of Extent and Impact of Cyberbullying and Traditional Bullying

\begin{tabular}{llcc}
\hline \multicolumn{1}{c}{ Dimension } & \multicolumn{1}{c}{ Type of Bullying } & Mean & $S D$ \\
\hline Extent & Cyberbullying & 2.76 & .46 \\
& Traditional Bullying & 2.96 & .39 \\
Impact & Cyberbullying & 2.61 & .05 \\
& Traditional Bullying & 3.18 & .04 \\
\hline
\end{tabular}

Hypothesis 3. Younger parents are more likely to identify and be familiar with mediums for conducting cyberbullying than older parents. Table 9 shows the means and standard deviations for scores on the Familiarity dimension by age group. Age (i.e., younger versus older parents) was not found to make a significant difference for a participant's familiarity with the media used for cyberbullying. Hypothesis 3 was rejected.

There was a significant difference, however, for age with regard to Family Internet Practices, ANOVA F(3,3.72) $=3.56, p=.02, \eta^{2}=.11$, a medium effect size. There were differences between 33-43 year olds and 55-65 year olds and between 44-54 and 55-65 year olds with regards to their family internet practices. The 33-43 year old age group believed it was more important to monitor and place restrictions on their child's internet use than did the 55-65 year old age group, $\mathrm{t}(39)=2.71, p<.01, d=.40$, a medium effect size. The $44-54$ year old age group also believed it was significantly more important to monitor and place restrictions on their child's internet use than did the 55-65 year old age group, $\mathrm{t}(57)=2.23, \mathrm{p}<.03, d=.28$, a small effect size. A hypothesis to this effect was not made, but an ANOVA was performed upon viewing the Family Internet Practices means for the age cohorts (See Table 10). 
Table 9

Age and Familiarity with Cyberbullying Mediums

\begin{tabular}{lcc}
\hline Age Group & Mean & $S D$ \\
\hline $22-32$ years old & 3.27 & .50 \\
$33-43$ years old & 3.28 & .55 \\
$44-54$ years old & 3.21 & .48 \\
$55-65$ years old & 2.93 & .28 \\
\hline
\end{tabular}


Table 10

Age and Family Internet Practices

\begin{tabular}{lcc}
\hline \multicolumn{1}{c}{ Age Group } & Mean & $S D$ \\
\hline $22-32$ years old & 3.50 & .53 \\
$33-43$ years old & 3.56 & .62 \\
$44-54$ years old & 3.43 & .59 \\
$55-65$ years old & 2.86 & .56 \\
\hline
\end{tabular}

Hypothesis 4. Parents are more likely to have learned about cyberbullying from television than any other media. Caregivers were found to have learned about cyberbullying more from television $(n=64)$ than any other resource $(n=23)$. Hypothesis 4 was retained.

Subsequently, t-tests were run to determine if the type of media that informed parents about cyberbullying produced differences in individuals' scores on the cyberbullying Dimension 2, Impact of cyberbullying, and Dimension 6, Preventative measures. Two significant differences were found. It was found that caregivers who learned about cyberbullying from television media believed cyberbullying to be significantly more impactful on victims than caregivers who stated they learned about cyberbullying from other media resources, $t(85)=2.48, p=.02, d=.30$, a medium effect size (See Table 11). It was also found that caregivers who learned about cyberbullying from television media believed potential preventative measures to be significantly more helpful in combating cyberbullying than caregivers who learned about cyberbullying from other types of media, $t(85)=2.65, p=.01, d=.32$, a medium effect size. (See Table 12). Hypotheses about the effects of television on perceived impact of cyberbullying and perceived helpfulness of preventative measures were not made, but t-tests were performed upon viewing the viewing the means for television and other media on the PPAC dimensions. 
Table 11

Media and Impact of Cyberbullying

\begin{tabular}{lll}
\hline \multicolumn{1}{c}{$\begin{array}{c}\text { Means learned about } \\
\text { Cyberbullying }\end{array}$} & Mean & $S D$ \\
\hline Television & & \\
Other Media & 2.98 & .41 \\
\hline
\end{tabular}


Table 12

Media and Prevention of Cyberbullying

\begin{tabular}{lll}
\hline \multicolumn{1}{c}{$\begin{array}{c}\text { Means learned about } \\
\text { Cyberbullying }\end{array}$} & Mean & $S D$ \\
\hline Television & & \\
Other Media & 3.23 & .35 \\
& 3.00 & .34 \\
\hline
\end{tabular}

Hypothesis 5. Parents perceive greater school involvement (micro-level) and the passage of new laws (macro-level) to be the most helpful preventative measures that can mitigate the prevalence of cyberbullying. A significant difference was found regarding different preventative measures to mitigate the presence of cyberbullying, ANOVA $F(2,5.19)=32.85, p<.001, \eta^{2}=.12$, a medium effect size. Tukey HSD analyses found that caregivers perceive greater school and law involvement to be a significantly more helpful preventative measure than both parental involvement, $\mathrm{t}(79)=3.42, \mathrm{p}<.001, d=.36$, a medium effect size, and no involvement, $\mathrm{t}(79)=3.42$, $\mathrm{p}<.001, d=.36$, a medium effect size. No significant differences were found between parental involvement and no involvement. Hypothesis 5 was retained. 
Table 13

\begin{tabular}{lcc}
\multicolumn{3}{l}{ Preventative measures' perceived impact on prevention of cyberbullying } \\
\hline \multicolumn{1}{c}{ Preventative Measures } & Mean & $S D$ \\
\hline School and law & 3.32 & .30 \\
involvement & & \\
No involvement & 2.73 & .24 \\
Parental involvement & 2.74 & .10 \\
\hline
\end{tabular}

\section{Qualitative Analysis}

Additional observations about participants' awareness and personal actions regarding cyberbullying can be made when looking at the narrative responses in the PPAC questionnaire. Participants were permitted to include more than one response (i.e., as many thoughts that they wished to express) to each open ended question. When asked about the ways that caregivers' monitor their child's use of the internet, a number of themes arose (See Table 14). The most frequent response to this question was "to check their activities" ( $n=50,54.3 \%)$ followed by "location of device/caregiver when child uses internet" $(n=41,44.5 \%)$. Other ways caregivers monitored their child's use of the internet included not allowing certain web pages $(n=24$, $26.1 \%)$, discussing their child's internet use with them $(n=13,14.1 \%)$, friend or follow the child on social media $(n=13,14.1 \%)$; and 8 caregivers $(8.6 \%)$ stated that have not monitored their child's internet use at all. 
Table 14

Different ways caregivers monitor their child's use of the internet

\begin{tabular}{|c|c|c|}
\hline Code & $\begin{array}{l}\text { Number of responses that include } \\
\text { this code }\end{array}$ & $\begin{array}{c}\text { Percentage of respondents } \\
\text { who use this method to } \\
\text { monitor }\end{array}$ \\
\hline
\end{tabular}

\begin{tabular}{|c|c|c|}
\hline $\begin{array}{l}\text { Check their activities (history, } \\
\text { passwords, etc.) }\end{array}$ & 50 & $54.3 \%$ \\
\hline $\begin{array}{l}\text { Location of devices/caregiver } \\
\text { when using internet }\end{array}$ & 41 & $44.5 \%$ \\
\hline $\begin{array}{l}\text { Parental controls/disallow } \\
\text { certain webpages }\end{array}$ & 24 & $26.1 \%$ \\
\hline Discussion & 13 & $14.1 \%$ \\
\hline $\begin{array}{l}\text { Friend/Follow them on social } \\
\text { media }\end{array}$ & 13 & $14.1 \%$ \\
\hline Don't monitor & 8 & $8.6 \%$ \\
\hline
\end{tabular}

In response to the question about the restrictions that caregivers place on their child's internet use several themes were present. The most common theme (See Table 15) was to place parental controls/block the child's access to the internet $(n=41,46.6 \%)$, followed by placing time restrictions on when the child can use the internet $(n=33,37.5 \%)$. Other pertinent themes that arose were: only allowing the child to use the internet in certain locations or under close parental supervision $(n=24,27.2 \%)$, having no restrictions on the child's use at all $(n=22$, 25.0\%), managing their child's accounts for them $(n=14,15.9 \%)$, and making their child be connected with them on social media (e.g., Facebook friends; $n=3,3.4 \%$ ). There was some overlap in themes between question 1 ways that caregivers' monitor their child's use of the internet and question 2 restrictions that caregivers place on their child's internet use. 
Table 15

Different restrictions caregivers place on their child's use of the internet

\begin{tabular}{lcc}
\hline \multicolumn{1}{c}{ Code } & $\begin{array}{l}\text { Number of responses that include } \\
\text { this code }\end{array}$ & $\begin{array}{c}\text { Percentage of respondents } \\
\text { who use this restriction }\end{array}$ \\
\hline Parental controls/Blocking & 41 & $46.6 \%$ \\
access & 33 & $37.5 \%$ \\
Time restrictions & 24 & $27.2 \%$ \\
Location/Physical supervision & 22 & $25.0 \%$ \\
No restrictions & 14 & $15.9 \%$ \\
Manage their child's accounts & & $3.4 \%$ \\
(password access, check & 3 & \\
activities) & & \\
Make them be connected on & & \\
social media (e.g., Facebook & & \\
friends) & &
\end{tabular}

In response to the question about other ways caregivers learned about cyberbullying several themes were present. The most common theme (See Table 16) was learning from other parents $(n=24,27.2 \%)$, followed by both TV/Movies and Schools $(n=20,22.7 \%)$. Other pertinent themes that arose about information resources were print media $(n=19,21.5 \%)$, none $(n=17,19.3 \%)$, personal experience (learned about from their child or witnessed it happen to their child) $(n=10,11.3 \%)$, the internet $(n=10,11.3 \%)$, and a caregiver's town $(\mathrm{n}=5,5.6 \%)$. 
Table 16

Other ways caregivers learned about cyberbullying

\begin{tabular}{llc}
\hline \multicolumn{1}{c}{ Code } & $\begin{array}{l}\text { Number of responses that include } \\
\text { this code }\end{array}$ & $\begin{array}{c}\text { Percentage of respondents } \\
\text { who use this code to monitor }\end{array}$ \\
\hline Other parents & 24 & $27.2 \%$ \\
Schools & 20 & $22.7 \%$ \\
TV/Movies & 20 & $22.7 \%$ \\
Print Media & 19 & $21.5 \%$ \\
None & 17 & $19.3 \%$ \\
Internet (blogs, websites, etc) & 10 & $11.3 \%$ \\
Personal Experience (learned & 10 & $11.3 \%$ \\
about from their child or & & \\
witnessed it happen to their & 5 & $5.6 \%$ \\
child) & 5 & \\
Town & 5 & \\
\hline
\end{tabular}

When asked to list the different types of media through which cyberbullying occur, caregivers listed 25 different responses (See Table 17). The medium that was listed most frequently was Facebook with 70 responses $(80.4 \%)$, followed by Twitter with 41 responses (47.4\%). Texting $(n=34,39.0 \%)$, email $(n=22,25.2 \%)$, and Instagram $(n=21,24.1 \%)$ were also some of the mostly frequently listed responses. A large number of venues were listed by only a handful of respondents, with 19 of the 25 venues had fewer than 10 responses each. A comprehensive list of the different types of cyberbullying media can be found below in Table 17 . 
Table 17

Different types of media through which cyberbullying occurs

\begin{tabular}{|c|c|c|}
\hline Code & $\begin{array}{l}\text { Number of responses that } \\
\text { include this code }\end{array}$ & $\begin{array}{l}\text { Percentage of respondents } \\
\text { who use this code to monitor }\end{array}$ \\
\hline Facebook & 70 & $80.4 \%$ \\
\hline Twitter & 41 & $47.4 \%$ \\
\hline Texting & 34 & $39.0 \%$ \\
\hline Email & 22 & $25.2 \%$ \\
\hline Instagram & 21 & $24.1 \%$ \\
\hline Chatrooms/Instant Messages & 14 & $16.0 \%$ \\
\hline MySpace & 9 & $10.3 \%$ \\
\hline Social Media (generic) & 9 & $10.3 \%$ \\
\hline Blogs & 7 & $8.0 \%$ \\
\hline Don't Know & 7 & $8.0 \%$ \\
\hline YouTube & 6 & $6.8 \%$ \\
\hline Facetime & 4 & $4.5 \%$ \\
\hline Chat via videogames & 4 & $4.5 \%$ \\
\hline Google + & 3 & $3.4 \%$ \\
\hline Snapchat & 3 & $3.4 \%$ \\
\hline AOL Instant Messenger & 2 & $2.2 \%$ \\
\hline Message Boards & 2 & $2.2 \%$ \\
\hline Websites created by others & 2 & $2.2 \%$ \\
\hline Voicemail/Talk on phone & 2 & $2.2 \%$ \\
\hline Skype & 2 & $2.2 \%$ \\
\hline Flickr & 2 & $2.2 \%$ \\
\hline Google chat & 1 & $1.1 \%$ \\
\hline Path & 1 & $1.1 \%$ \\
\hline Pinterest & 1 & $1.1 \%$ \\
\hline Tumblr & 1 & $1.1 \%$ \\
\hline
\end{tabular}


In response to the question about obstacles that prevent youth from getting help, a variety of themes emerged. The most common theme (See Table 18) was Fear ( $n=37,42.0 \%$ ), followed by Not Being Comfortable Telling an Adult/not Thinking They Will be Taken Seriously by an Adult ( $n=31,35.2 \%)$. Other frequent themes present in the responses included Embarrassment $(n=30,34.0 \%)$, Social Pressure $(n=12,13.6 \%)$, Feelings of Helplessness or Depression $(n=$ 10, 11.3\%), Don't Know Who to Go to For Help (9, 10.2\%), and Don't Know/Not Sure (5, 5.6\%). Other pertinent themes can be found in Table 18 . 
Table 18

Obstacles prohibiting youths from getting help

\begin{tabular}{lcc}
\hline \multicolumn{1}{c}{ Code } & $\begin{array}{l}\text { Number of responses that include } \\
\text { this code }\end{array}$ & $\begin{array}{c}\text { Percentage of respondents } \\
\text { who use this code to monitor }\end{array}$ \\
\hline Fear & 37 & $42.0 \%$ \\
Not comfortable telling an & 31 & $35.2 \%$ \\
adult/think they won't be & & \\
taken seriously & 30 & $34.0 \%$ \\
Embarrassment & 12 & $13.6 \%$ \\
Social Pressure & 10 & $11.3 \%$ \\
Feelings of helplessness or & & $10.2 \%$ \\
depression & 9 & \\
Don't know who to go to for & & $9.0 \%$ \\
help & 8 & $5.6 \%$ \\
Lack of laws/school's ability & 5 & $7.9 \%$ \\
to help & 7 & $7.9 \%$ \\
Retaliation & 5 & $5.6 \%$ \\
Might get in trouble & 5 & \\
Don't know/Not sure & & \\
Anonymity of bully & & \\
\hline
\end{tabular}

When asked about additional ways that cyberbullying can be better addressed, several themes emerged. These were: Parents being more proactive and involved $(n=19,22.0 \%)$ as well as raising awareness $(n=19,22.0 \%)$ emerged as the most common themes. Harsher punishments/stricter consequences $(18,20.9 \%)$ theme was also a common in respondents' statements. Other themes that were present in the data included creation of groups or programming to combat cyberbullying $(n=14,16.2 \%)$, opening up communication $(n=12$, $13.9 \%)$, and limiting use of electronics and/or social media $(n=11,12.7 \%)$. A number of 
respondents $(n=12,13.9 \%)$ stated that they did not know or that there were not any other ways to address cyberbullying. A comprehensive list of all themes can be found in Table 19 . 
Table 19

Additional ways respondents think cyberbullying can be addressed

Code Number of responses that include

Percentage of respondents this code who use this code to monitor

\begin{tabular}{lcc}
\hline Parents more & 19 & $22.0 \%$ \\
proactive/involved & 19 & $22.0 \%$ \\
Raise awareness & 18 & $20.9 \%$ \\
Harsher punishments/stricter & & \\
consequences & 14 & $16.2 \%$ \\
Creation of parent groups or & 12 & \\
programming & 12 & $13.9 \%$ \\
Don't know/None & 11 & $13.9 \%$ \\
Open up communication & & $12.7 \%$ \\
Limit use of electronics/Social & 6 & $6.9 \%$ \\
media & 5 & $5.8 \%$ \\
Increase in laws & 3 & $3.4 \%$ \\
Increased media attention & 2 & $2.3 \%$ \\
Culture change needed & & \\
Greater involvement by & & \\
websites where cyberbullying & & \\
occurs & & \\
\hline
\end{tabular}

When asked the question "what does cyberbullying mean to you," a variety of themes emerged from individuals' responses. The most frequent theme was any online abuse with the intent to cause major harm $(n=40,43.0 \%)$. Caregivers made statements such as "cyberbullying is anyone who is causing emotional harm to another person on the internet," "a person publicly humiliating, threatening, teasing, causing emotional harm via the internet to another person" and “tormenting a person using digital means (email, texts, social media, etc.)" Another common 
theme was any electronic abuse with the intent to cause minor harm $(n=15,16.1 \%)$. Examples of this theme include "when kids use technology like the internet to pick on other kids", "people online that influence other people for the worse", and "any online activity that targets one or more people". Other relevant themes included using social media (exclusively) for abuse/harm ( $n$ $=1212.9 \%)$, that cyberbullying is an extension of traditional bullying $(n=11,11.8 \%)$, and, in addition, there was also no mention of technology/internet at all $(n=10,10.7 \%)$. A comprehensive list of all themes can be found in Table 20. 
Table 20

What cyberbullying means for respondents

\begin{tabular}{lcc}
\hline \multicolumn{1}{c}{ Code } & $\begin{array}{l}\text { Number of responses that include } \\
\text { this code }\end{array}$ & $\begin{array}{c}\text { Percentage of respondents } \\
\text { who use this code to monitor }\end{array}$ \\
\hline $\begin{array}{l}\text { Any electronic abuse with the } \\
\text { intent to cause major harm }\end{array}$ & 40 & $43.0 \%$ \\
Any electronic abuse with the & 15 & $16.1 \%$ \\
$\begin{array}{l}\text { intent to cause minor harm } \\
\text { Social media (exclusively) for }\end{array}$ & 12 & $12.9 \%$ \\
harm & 11 & $11.8 \%$ \\
$\begin{array}{l}\text { Extension of traditional } \\
\text { bullying }\end{array}$ & 10 & $10.7 \%$ \\
No mention of & & \\
technology/internet & 3 & $3.2 \%$ \\
Something to protect your kids & & \\
from & 2 & $2.1 \%$ \\
Parents did not do their job & & \\
\hline
\end{tabular}

In response to the question about how respondents see cyberbullying as a problem, a number of themes emerged. The most prevalent theme was that cyberbullying damages selfworth and causes depression/isolation $(n=28,30.4 \%)$. Other important themes included: cyberbullying spreads rapidly and has a larger reach than traditional bullying $(n=20,21.7 \%)$; anonymity makes cyberbullying hard to stop and gives power to the bully $(n=20,21.7 \%)$; can lead to suicide ( $n=17,18.4 \%)$; and it is hard to monitor $(n=11,11.9 \%)$. A comprehensive list of all themes can be found in Table 21. 
Table 21

How respondents see bullying as a problem

\begin{tabular}{lll}
\hline \multicolumn{1}{c}{ Code } & $\begin{array}{l}\text { Number of responses that include } \\
\text { this code }\end{array}$ & $\begin{array}{c}\text { Percentage of respondents } \\
\text { who use this code to monitor }\end{array}$ \\
\hline Damages self-worth and & 28 & $30.4 \%$ \\
causes depression/isolation & 20 & $21.7 \%$ \\
Spreads rapidly/larger reach & 20 & $21.7 \%$ \\
Anonymity makes it hard to & & \\
stop and gives power to the & & \\
bully (makes them more likely & & \\
to say things they wouldn't & 17 & $18.4 \%$ \\
say to someone's face) & 11 & $11.9 \%$ \\
Can lead to suicide & 11 & $11.9 \%$ \\
Hard to monitor & & \\
Hard to disconnect/can't & & \\
escape the bullying & 2 & $2.1 \%$ \\
It is a serious problem & $3.2 \%$ \\
It is the parents' fault & 2 & $2.1 \%$ \\
Detracts from school & & \\
performance & & \\
Schools don't do more & & \\
\hline
\end{tabular}

\section{Summary}

Four out of the five hypotheses were retained after conducting analyses. Hypothesis 1 , a majority of parents believe that cyberbullying is a problem that should be better addressed, was retained. Hypothesis 2, a majority of parents perceive children's experiences of cyberbullying to have less of a negative impact on their children than traditional bullying, was also retained. Hypothesis 3, younger parents are more likely to identify and be familiar with mediums for conducting cyberbullying than older parents, was not supported by data, and, therefore, rejected. 
Hypothesis 4, parents are more likely to have learned about cyberbullying from television than any other media, was retained. Hypothesis 5, parents perceive greater school involvement and the passage of new laws to be the most helpful preventative measures that can mitigate the prevalence of cyberbullying, was retained.

Beyond the stated research hypotheses, additional analyses were performed. It was found that 33-43 year olds believed it was significantly more important to monitor and place restrictions on their child's internet use than 55-65 year olds did. It was also found that 44-54 year olds also believed it was significantly more important to monitor and place restrictions on their child's internet use than 55-65 year olds did. It was found that caregivers who learned about cyberbullying from television media believed cyberbullying to be significantly more impactful on victims than caregivers who learned about cyberbullying from other media resources. Additionally, caregivers who learned about cyberbullying from television media believed preventative measures to be more helpful than caregivers who learned about cyberbullying from other media sources. Further, school and law involvement together was perceived to be a significantly more helpful preventative measure than both parental involvement and no involvement.

Qualitative data yielded a number of findings that added richness to the study's results. Responses were gathered from 8 open-ended questions resulting in more in-depth themes related to topics, such as parental monitoring of children's internet use, parental restrictions on children's internet use, and obstacles for youth to getting help when they are cyberbullied. The other qualitative themes that emerged were about how parents learned about cyberbullying, what cyberbullying means to them, how cyberbullying is a problem, through what media cyberbullying occurs, and how cyberbullying can be better addressed. 


\section{Conclusion}

This study investigated a number of hypotheses to better understand caregivers' awareness and perceptions of cyberbullying. It investigated this topic from both a quantitative and qualitative perspective, finding a number of significant results. Chapter 5 discusses these findings, their implications for stakeholders like children, their parents, and schools, and connects the findings to the relevant available literature. Furthermore, Chapter 5 discusses the limitations of the study and suggests future directions for research. . 


\section{Chapter 5: Discussion}

The author conducted a survey study on parents'/caregivers' perceptions and awareness of cyberbullying. One measure was employed as part of the survey, and qualitative data from open-ended questions supplemented the objective questionnaire's findings. The author-created measure was found to have strong internal consistency reliability, and additional comments by participants added richness to the quantitative findings. This chapter focuses on discussing the significant findings and frames these in the context of the literature reviewed in Chapter 2 and additional literature that was read to understand the findings. Limitations to the study are noted, followed by recommendations for future research.

\section{Participant Demographics}

Despite the fact that $72.4 \%$ of people in the United States identify as Caucasian/White American (US Census, 2010), 90.9\% of the participants reported being Caucasian/White American. Furthermore, the population of the United States is comprised of $16.3 \%$ Latinos, 12.6\% African Americans, 4.8\% Asian, and 2.9\% Biracial/Multiracial (US Census, 2010). Participants in this study were comprised of 3\% African Americans, 1\% Asian Americans, 3\% Latinos, and 2\% Biracials/Multiracials. The discrepancy between the racial and ethnic composition of the United States and that of the study's sample makes it difficult to draw any inferences about the impact of race, culture, and ethnicity on cyberbullying awareness and perceptions. Furthermore, the discrepancy limits the generalizeability of the study. It failed in adequately investigating the cyberbullying awareness of minorities. A recent Pew report (September 25,2013 ) indicated that $15 \%$ of the U.S. adult population does not have direct home or personal access to the internet. This population appears to be rural and poor. It is assumed that the study's survey did not reach this population. The study may be understood within the social 
contexts of New England White, middle class, married, and educated parents and caregivers of children attending primary school through undergraduate college.

Another concern for the present study was that female participants (76.8\%) were disproportionately represented in the sample. It is not clear why there was such a difference between the number of male and female participants. One possible explanation is that female caregivers may be better connected to their fellow caregivers and thus forwarded the announcement of the study to their female peers. It is also possible that more mothers than fathers are directly involved in the care of their children and may be more emotionally invested in preventing cyberbullying and traditional bullying. Lastly, Chibbaro's (2007) assertion that cyberbullying is more relationally aggressive, and thus more prevalent among females, may cause mothers to be more alert and sensitive to instances of cyberbullying than their male counterparts.

Additionally, the social class of the study's sample may have affected results. Most of the participants were from the middle and higher classes, with only $9 \%$ stating that they were poor or unemployed. The most recent United States Census cited that $16 \%$ of the population lives below the poverty line, with $20 \%$ of children living in poverty (CBS Washington, 2012).The difference in the study's sample from the general population of the United States raises the question whether families with more economic resources find themselves with more time to monitor their children's internet use, cyberbullying, or be involved in their child's schools. Furthermore, having more economic resources may allow for participants' children to attend better or smaller schools that have the capacity to inform children and families about cyberbullying and where the extent and impact of cyberbullying may be lower than in schools with less resources. The survey, however, did not ask about the type of schools the participants' children attended. 


\section{Significant Findings}

The primary goal of the study was to gain information regarding caregiver awareness and perceptions of cyberbullying. There is no published work on this topic. Despite this lack of scholarship, the author utilized available related literature to understand the results of the study. Furthermore, several significant findings of the study will help to inform future studies of areas that need more investigation.

Beliefs of extent of cyberbullying. The study affirmed the author's hypothesis that a majority of caregivers believe that cyberbullying is a problem that should be better addressed. This is consistent with Ybarra et al.'s (2007) assertion that the risks of the internet to adolescent mental health are being increasingly recognized. As more than three quarters of present study's participants believed that cyberbullying is a problem that should be addressed, it appears that there is increased public awareness owing to various media outlets on the untimely deaths of cyberbullying victims, such as, Tyler Clementi, Ryan Halligan, and Megan Meier. Parents want a solution to the cyberbullying problem. On the basis of the agreement of three-fourths of the parents, the author's decision to make $50 \%$ the threshold for "majority" was as an underestimation of parents' concerns or information about the prevalence cyberbullying. The $50 \%$ threshold was decided along normative lines because the author expected a representative sample of parents from around the nation, which was, however, not the case because the respondents were mostly educated, middle class people from Northeast United States. However, despite the fact that more than $75 \%$ of caregivers agreed that cyberbullying is a problem, there is a substantial number of caregivers who do not believe this to be a problem that needs pressing attention. Even well-established researchers of school bullying have not differentiated cyberbullying from traditional school bullying (e.g., Espelage, Rao, \& Craven, 2013). Why a 
minority of caregivers in the study did not believe cyberbullying to be a problem that needs to be better addressed is discussed briefly when the qualitative results are interpreted, but this topic needs further investigation for more cogent explanations.

Cyberbullying versus traditional bullying. Results from the study indicated that there are differences in caregivers' perceptions of cyberbullying and traditional bullying. Caregivers believed that traditional bullying is both significantly more extensive and has a more negative impact on the lives of children than cyberbullying does. Parents in the study perceived low risk from cyberbullying despite findings that cyberbullying can lead to major depression, social anxiety, serious levels of stress, and suicide (Dehue et al., 2008; Juvoven \& Gross, 2008; Ybarra, 2004). While a majority of caregivers believed that cyberbullying was a problem that needed to be addressed, caregivers did not ascribe dangerousness to cyberbullying. A possible explanation for this difference can be found in the assertion that many parents are unaware when cyberbullying is occurring (Dehue et al., 2008) and, thus, have difficulty attributing a child's distress symptoms (e.g., depression) to cyberbullying.

Age and familiarity with cyberbullying mediums. The lack of a significant finding between age and familiarity with the media used for cyberbullying is interesting as it dispels the notion that younger caregivers, traditionally seen as more technologically savvy, are the most familiar with new media. This may, in part, be accounted for by the recent increase in older adults using social networking websites. The Pew Research Center recently found that $52 \%$ of adults between 50-64 years old use social networking websites (Brenner, 2013). As older adults are becoming more familiar with social networking and having an online presence, they are simultaneously increasing their awareness of the type of media used for cyberbullying.

There were significant differences between age groups for family internet practices. 
Significant differences were found between 33-43 year olds and 55-65 year olds and between 44-54 year olds and 55-65 year olds. In both cases the younger age group believed it was significantly more important to monitor and place restrictions on their child's internet use than the older group.

The significant differences found between two younger age groups and the oldest age group need further investigation. The study did not investigate why certain age groups place greater importance on monitoring and placing restrictions on their child's internet use. Qualitative data from the study helped to provide some understanding about the type of monitoring older caregivers utilize. Examples of responses by 55-65 year olds included "I have a Facebook account so that I can keep an 'eye' on my child's account, but realize this is not a foolproof method. My children are older now and have a better understanding of how to protect themselves"; there were references to having "Discussions about risk, risky behaviors. Daughters are college age - they need to have guidance rather than restrictions at this age." These responses raise the notion that the difference the importance placed on monitoring internet behavior between older adults and the other two age groups is that the children of older adults are much more likely to be older and in need of guidance rather than monitoring or restrictions. To gain a better understanding of this, future research should look at caregivers' beliefs about the monitoring and restriction on internet use for children from varying age groups. Furthermore, future investigations should look at attitudes towards placing restrictions on and monitoring children's internet use, caregiver awareness of how to monitor or place restrictions on internet use, and what caregivers believe are the most effective practices they can take part in to help curb cyberbullying.

Media and cyberbullying. Caregivers were found to have learned about cyberbullying 
more from television than any other resource. Radio and print media may need to report on cyberbullying more than they do currently. It is also possible that these news resources pay more attention to adults than to children, their parents, and families. Of particular interest were the two additional findings that caregivers who learned about cyberbullying from television believed it to have impact on victims more than caregivers who learned about cyberbullying from other media resources; and that potential preventative measures would be helpful in combating cyberbullying significantly more the other parents. One implication could be that television media coverage, which is often about the suicides caused by cyberbullying, has been effective in raising awareness about the impact of cyberbullying. The difference in the effect of seeing these stories on television rather versus reading about them in print media, or hearing about them on the radio, from other parents, or from schools needs to be investigated. The different modalities of input, such as, seeing, hearing, live observation, personal experience, etc. may be contributing influences which need to be studied.

Preventative measures. The study found that there were significant differences between caregivers' beliefs on the effectiveness of different preventative measures aimed at reducing cyberbullying. Both greater school involvement and the passage of new laws were believed to be significantly more helpful preventative measures than both parental involvement and no involvement. While it is difficult to ascertain why caregivers believed school and law involvement to be the most helpful measures, an argument can be made that schools are historically the venue where most traditional bullying intervention occurs. Due to the historical manner in which schools have had to handle problems of this nature in the past, it is possible that caregivers believe that they can adequately address cyberbullying as well.

Also of interest is the finding that no significant differences were found between the 
beliefs of the effectiveness of parental involvement and no involvement whatsoever. Without further research it is difficult to understand the meaning behind a lack of a significant difference between parental involvement and no involvement. Further research can help clarify, however, if this is due to caregivers' harboring beliefs that the preventative measures they implement are ineffective. Caregivers' reports of low self-efficacy beliefs about intervening with cyberbullying needs to be further explored. One interpretation about parents' low self-efficacy is that the most parents have not had to deal with cyberbullying personally (due to their age) and thus do not have lessons from personal experiences to draw from when conceptualizing how to prevent cyberbullying. Further research is needed to determine if caregivers feel a sense of learned helplessness regarding the prevention of cyberbullying due to either their own experiences with failing to prevent cyberbullying or negative experiences they have learned about through both peers and the media.

Caregivers believed that schools and new legislation can play a vital role in the prevention of cyberbullying. The potential impact of both the passage of new laws and greater school involvement was seen further in the qualitative data. Caregivers referred to an absence of laws/schools' ability to help as to what prohibits youths from getting help if they are cyberbullied. Some examples of this point included "I believe a major obstacle for the child to get help is that many states do not have laws against cyberbullying, and, schools do not enforce [rules against] any type of bullying that happens off of school grounds...." as well as "Schools don't always respond appropriately, thinking that if it doesn't happen on school grounds, they aren't responsible."

In contrast to the assertions by caregivers in the study, Espelage, Rao, and Craven (2013) outline some ways that schools were effective at addressing bullying, and how it may be 
effective with cyberbullying too. They argue that anti-bullying interventions that target the whole school community (students, teachers, and parents) in ways that change the school ethos are effective. They propose that changing the culture at a school to where bullying is no longer condoned by peers and, thus, no longer results in enhanced self-perceptions by the bully is a potent intervention program that can combat traditional bullying and cyberbullying (Espelage et al., 2013).

Caregivers in the present study were asked to list additional ways they believe that cyberbullying can be addressed. One caregiver stated "I believe if there were laws against cyberbullying, more children would be dissuaded from perpetrating cyberbullying. If there are serious consequences to their actions, they will be less likely to participate in cyberbullying". This quotation represents several other beliefs of caregivers that referred to harsher consequences, often through legislation, as necessary to curb cyberbullying. Thus the emphasis was on the punishment of cyberbullies than on prevention programming for students, teachers, staff, and parents that educate all stakeholders on how to intervene before the actual cyberbullying occurs, as recommended by Espelage at al. (2013).

\section{Qualitative Findings}

The study utilized qualitative data to gain a deeper understanding of parents' perceptions and awareness of cyberbullying. In fact, the open-ended questions elicited answers that clarified responses to Likert-type items. Themes that emerged from qualitative data are presented in the context of available literature and scientific findings.

What cyberbullying means to caregivers. Several themes were present in the data regarding what cyberbullying meant to the caregivers. Caregivers used their own words to describe cyberbullying and seven themes were present. Almost $60 \%$ of the responses agreed that 
cyberbullying is electronic abuse with the intent to cause harm, with the only difference being the emphasis placed by caregivers how much harm it can cause (i.e., lead to suicide versus teasing). This finding is encouraging as a majority of parents appeared to agree on what cyberbullying is and that it causes some sort of harm.

Despite a majority of caregivers having similar responses about cyberbullying, a number of them offered responses that differed for a variety of reasons. Of particular interest is the theme that cyberbullying is an extension of traditional bullying. The study found that parents believed that traditional bullying has greater impact on children than cyberbullying, and a number of parents saw cyberbullying as an extension of traditional bullying. One caregiver wrote "Individuals being hurtful primarily mentally to another person. This could lead to or follow physical altercations between both parties. It's my belief that cyberbullying is an extension of general bullying," The literature, in fact, agrees that cyberbullying, in some cases, may be an extension of traditional bullying. Juvonen and Gross (2008) found that students who have been identified as a bully, victim or bully-victim at school are at a higher risk than their peers to become involved with cyberbullying. Furthermore, Espelage et al. (2013) found that there is a strong argument that bullying perpetration is an antecedent of cyberbullying perpetration in middle school. They theorized that as children get older and increase their engagement with technology, cyberspace becomes another context within which bullying perpetration occurs.

Additionally, in the present study, some caregivers differed greatly in their opinions by stating that cyberbullying meant that "parents did not do the right thing" and "parents didn't do the job they should have." These sentiments vary greatly from other opinions and help to highlight the range of beliefs that caregivers have about cyberbullying. Parents may be confused about cyberbullying, its cause, process, and outcome. 
How respondents see cyberbullying as a problem. . The most prevalent theme, and one that is consistent with findings in the literature (Hinduja \& Patchin, 2007; Ybarra et al., 2007), is that cyberbullying damages self-worth and causes depression and isolation. One caregiver stated that "[cyberbullying] destroys ego, self-worth, isolates the child socially" and another stated "it lowers children's self-esteem and drives them into depression." These responses are consistent with Ybarra et al.'s (2007) study that showed that victims of cyberbullying are significantly more likely than their peers to report psychosocial problems, including depression. Cyberbullying can lead to suicide was another prominent theme in the responses to the study. Caregivers stated "it is a problem because children are killing themselves" and "teenage to college age students committing suicide because of cyberbullying." In addition to the theme of suicide being prominent in print and television media, primarily due to the suicides of Tyler Clementi, Ryan Halligan, and Megan Meier, it is being studied in the literature. Initial findings suggest that victims of cyberbullying are at much higher risk for suicidal ideation than their peers (Hinduja \& Patchin, 2007). Furthermore, some findings suggest that cyberbullying has the potential to cause greater psychological and emotional pain to victims than traditional bullying (Ybarra \& Mitchell, 2004). This is believed to occur because of the larger reach of cyberbullying where victims can be victimized even when the bully is not physically present (Law et al., 2012). Similarly parents commented "it [cyberbullying] puts torment and bullying on a larger spectrum and in front of a larger audience" and "they are more widely exposed to bullying than they would be without it [cyberbullying].”

How caregivers monitor their child's use of the internet. Caregivers listed the different ways, if any, that they monitor their child's internet use. Over $90 \%$ of caregivers stated that they monitor their child's internet use in some manner. Some of these parents also stated that 
despite monitoring their child's internet use, they realized their efforts were not sufficient or foolproof. One caregiver stated "When our youngest wanted to set up a Facebook account in his freshman year, I agreed under the condition that he "friend me." I realize now that he could have blocked what I was looking at, but at the time I thought I was pretty smart.” Other caregivers indicated that they try to be more covert in their monitoring of their child's internet activity. One caregiver stated that "I secretly monitor my child on twitter" as her means of keeping up with their child's internet use. While the literature is yet to indicate whether or not any type of monitoring is most helpful in identifying or stopping cyberbullying, results from the present study suggested that most parents felt that some type of monitoring is necessary. Furthermore, checking their child's internet activities and being present in the room while their child uses the internet appeared to be the most frequently used forms of monitoring. Future research should look more closely at parental monitoring of internet use by their children in order to determine if monitoring is helpful, and if so, what type of monitoring has the greatest impact on mitigating cyberbullying.

Restrictions caregivers place on their child's use of the internet. Caregivers indicated the different restrictions, if any, that they place on their child's internet use. In total $75 \%$ of caregivers placed some form of restrictions on the internet, which is consistent with current literature (Dehue et al., 2008) that indicates more than half of parents set rules for their children about what they could do on the internet and how often they could use it. A number of caregivers (25\%), though, indicated that they did not place any restrictions on their child's internet use. While some of these caregivers stated that their child was too old to place restrictions on, others indicated that they did not place restrictions for reasons such as "I trust him to make good decisions." 
Other ways caregivers learned about cyberbullying. There is a concern about the current lack of consistency in the ways that caregivers are learning about cyberbullying. The variety of answers ( 8 different responses) indicates that caregivers were learning about cyberbullying from not only the media but also from schools, towns, their children, and other caregivers. The lack of consistency in the responses suggests that a majority of caregivers may be in need of formal training and education about cyberbullying. Of particular concern is that schools were only listed in $22.7 \%$ of responses as a source of knowledge. Given that few school professionals believe they are equipped to deal with cyberbullying among students (Slovak \& Singer, 2011), it is not surprising that schools are not more proactive in educating caregivers about its existence and how to reduce it (Beran \& Li, 2005).

Different types of media through which cyberbullying occurs. Facebook was mentioned by over $80 \%$ of the respondents, and no other medium was cited by over $50 \%$ of caregivers, despite 25 different media types being listed. Indications from this lack of consistency suggest that caregivers do not have an awareness of diverse cyberbullying mediums. In other words, caregivers could name many of the different cyberbullying mediums as a group, but were largely unaware of the vast number of cyberbullying mediums that exist. This finding is consistent with the finding that school social workers are unfamiliar with the different technologies used for cyberbullying (Slovak \& Singer, 2011). Some responses by caregivers, such as AOL instant messenger, also indicate an understanding of cyberbullying mediums used by previous generation of students but not by the current generation.

Obstacles prohibiting youth from getting help. Caregivers identified 11 different obstacles that they believed children must overcome in order to reach out for help when being cyberbullied. A total of $35.2 \%$ of caregivers responded that not feeling comfortable telling an 
adult was an obstacle. Literature (Diamanduros et al., 2008) has indicated that over half of children do not report incidents of cyberbullying to their parents or other adults. Diamanduros et al. did not explicitly study why children did not report cyberbullying to caregivers; however, not feeling comfortable telling an adult, as found in the present study, is one of the leading hypotheses that needs to be studied. Caregivers also cited a school's inability to help due to laws and restrictions as an obstacle children need to overcome. This difficulty is also seen for school administrators (Kowalski \& Limber, 2007) who have difficulty figuring out how they can intervene because cyberbullying occurs off school grounds. Only 5.6\% of respondents indicated that they did not know or were not sure of the obstacles that the youth needs to overcome.

Additional ways caregivers think cyberbullying can be addressed. The two most popular responses were parents being proactive/involved and raising awareness about cyberbullying (both with $22 \%$ ). Of particular interest is that "parents being more proactive" was the most popular qualitative response contradicting the study's quantitative finding that there was no significant difference between the perceived effectiveness of caregiver involvement and no involvement whatsoever. This discrepancy between quantitative and qualitative data raises questions about there being a split between caregivers who believe parental involvement can be effective and those who believe it cannot be helpful. Some parents provided statements, such as, "Like every other behavior issue, an involved parent can make a huge impact" and "As with most things 99.9 percent of the job falls on the parents." This differs from another group of caregivers who commented that parents aren't helpful in preventing cyberbullying because "too many parents are not tech savvy enough to even know where to start." Additional investigation is necessary to understand the reasons behind differences in parental involvement, as well as on parental self-efficacy beliefs about intervening with their children's use of the internet with 
regard to the new phenomenon of cyberbullying.

A minority of parents (3.4\%) indicated that a broader cultural change is necessary to best address cyberbullying. One caregiver stated that "children do not attend church or religious services and do not sense that they are under the law or authority; even many first graders do not have fearful respect for adults or consequences." Also very importantly, some respondents commented that "many parents model extreme dependency on communicating via social network[s] by constantly being on their phones and Facebook, etc: I am truly concerned for the soul of our culture." Another caregiver responded, "The question assumes that all forms of bullying are bad...I think schools should be more concerned with educating students on the three R's rather [than] on the other nonsense. Maybe if the curriculum standards were higher and the kids needed to concentrate more on the actual education, they wouldn't have so much time for this other stuff." The current literature has not investigated the role of cultural shifts on the prevalence of cyberbullying. It is apparent that caregivers have a wide range of ideas about how cyberbullying can be better addressed and looking at culture is one domain that needs to be researched in the future. A focus group with parents could address this issue.

\section{Limitations}

Design. There were several limitations to the study. One limitation was that the study was not designed to show causal relationships; rather the study was exploratory and correlational in nature with the goal of gathering descriptive information to inform future research, practice, and training. The limitations inherent in this type of study included (a) a geographically limited sample that is not generalizable, (b) a relatively small sample size, and (c) methodological flaws of a self-report survey. Furthermore, there was a selection bias in the sample because individuals who knew how to navigate the internet were the ones that took the survey. Individuals who were 
not familiar with the internet were not able to take this survey as it was administered through a website. Therefore, parents who worked at several jobs and had no time, who were poor, who had low education, and whose dominant language was not English, such as foreign-born first-generation immigrants, were not likely participants of the study. The recruitment announcement for the study should have been posted on the websites of minority professional organizations in mental health services, such as APA's African American, Native American, Asian American, and Latino Psychological Associations, APA Division 45, Society for the Psychological Study of Culture and Racial and Ethnic Minority Issues, APA Div 17's Section of Ethnic and Racial Diversity (SERD), Association of Black Psychologists (ABPsi), and the American Counseling Association's division, Association for Multicultural Counseling and Development. Racial and ethnic minority professionals would have forwarded the announcement to their cultural networks of family and friends.

\section{Recommendations}

Training and intervention. The results from the study offer initial thoughts on what training and intervention are necessary to help prevent or combat cyberbullying and raise parental awareness of cyberbullying. One area of intervention and training is to focus on informing caregivers about the serious negative impact of cyberbullying on the youth. While caregivers believed that cyberbullying is a problem that needs to be addressed, they also believed that traditional bullying is significantly more harmful than cyberbullying. Training and intervention need to focus on raising caregivers' awareness that cyberbullying is a development or permutation of bullying in a rapidly changing technological society. Parents need to be familiar with all types of bullying that children are subjected to.

Another recommendation includes training on the available options to restrict or monitor 
children's internet access. While many caregivers in the study engaged in some form of restriction or monitoring of their child's internet practices, a number stated that they realized what they did was not sufficient. Such training will help parents make better decisions about what internet practices are best for their own family. Training should also focus on the multitude of venues where cyberbullying occurs and about the rapidly changing nature of the venues where it occurs. While most parents in the study could identify Facebook and Twitter as venues for cyberbullying, other prominent venues, such as Snapchat (3.4\% of parents) and Tumblr (1.1\%), were largely unknown. Furthermore, former cyberbullying venues, such as, AOL instant messenger, were still being identified by some parents as cyberbullying locales. Updates in training will inform not only about the current most popular digital media, but also how to best stay up-to-date as new media become popular and others fall out of use.

While television is an important source of news and information, the study highlights the need for schools, parent groups, communities, and other groups to increase their efforts at reaching out to parents and talking with them about cyberbullying. A number of caregivers commented in the open-ended questions that they learned about cyberbullying from their child's school; however, education of parents by schools needs to increase significantly so that caregivers can learn about the extent and impact of cyberbullying. Additionally, this training needs to begin when the children are still young and parents can begin to incorporate their training into their family internet practices. School counselors need to come to classes and also hold small counseling groups to discuss with students about cyberbullying, whether they have experienced it, and how they can prevent or report it. This open discussion in schools about cyberbullying may make children less uncomfortable about reporting on their cyberbullying experiences. 
Public policy. New Jersey's recent law requires schools to handle alleged bullying within a strict time frame and to make efforts to stop bullying outside of school grounds if the bullying affects school operations and the rights of other students (Rundquist, 2012). Furthermore, New Hampshire passed a law in 2010 requiring schools to have policies against cyberbullying. This law revised a previous law passed in New Hampshire, the Pupil Safety and Violence Prevention Act, which mandated schools to create policies against traditional bullying (Jorgensen, 2010). Dr. William Slammon, the school psychologist at Winchester Public School, NH, said (personal communication, 10-14-13) that his school is vigilant about cyberbullying in and outside the school premises and can easily track and catch cyberbullies because these children are not sophisticated enough to know how to maintain their anonymity in internet communication processes. Cyberbullying needs to be addressed at multiple levels: home, school, community organizations, places of worship, teacher and mental health organizations, and state and federal governments. Research on the effectiveness of involvement at each level of society is needed. In addition, focusing time, funds, and efforts simultaneously and conjointly at different ecological systems, micro, meso, exo, and macro systems, may prove to be more productive at helping the most number of people than ad hoc decisions made by individual members or units that can only help a few, such as one's own children and local community.

\section{Future Research}

Future research needs to be conducted on a variety of aspects of cyberbullying. Of most importance is a study that focuses on which interventions or trainings are most helpful in increasing parents' awareness of cyberbullying and in changing their family internet practices. There is also a need for additional research on which family internet practices are most helpful in the prevention of cyberbullying. While placing restrictions and monitoring children's internet use 
are assumed to be helpful in combating cyberbullying, the current literature does not indicate which of these practices is most helpful and which are not helpful at all. A greater understanding of the usefulness of these practices is necessary to help caregivers best focus their efforts at preventing or combating cyberbullying.

Research also needs to be conducted at the school level to help determine practices, besides educating families about cyberbullying, that schools can partake in to combat cyberbullying. Furthermore, the impact of recent legislation about cyberbullying, such as by New Jersey, needs to be researched in order to determine if it is helpful and should be adopted by other states.

\section{Food for Thought}

This study leaves psychologists with the question "what can we do with these findings?" First and foremost, psychologists need to evaluate how they can help raise caregiver awareness of cyberbullying through both their own clinical practice and through their presence in the community by providing prevention education through community lectures and brochures. Discussions with the caregivers of a clinician's child clients can easily increase awareness about cyberbullying. Furthermore, clinicians can maximize their impact by participating in (or organizing) community discussions or focus groups about the topic. Even though clinicians may not have all of the answers, they can ask the right questions to persuade caregivers to reflect on and think about their own approach to cyberbullying with their children. If a parent is abusive with his or her children, verbally or physically, could it be possible that his or her child/children may imitate parental aggression and anger in internet communications with peers perceived to be weak, different, or odd? Such a possible consequence of parental abuse on children could be discussed in therapy with parents who are alleged to be abusive in their parenting. In addition to 
raising awareness, clinician's need to evaluate how they might approach a situation in clinical practice where a client or a client's child is being cyberbullied or is cyberbullying someone else. Thoughtful consideration is needed with regard to whether or not cyberbullying should be approached how traditional bullying is approached, or if a new approach is warranted given the nuances, subtleties, and invisible aspects of cyberbullying, when compared to the obviousness of physical bullying, name-calling, and hateful language and slurs. In some ways this study leaves clinicians with more questions than answers, but it does provide an initial or exploratory framework from which clinicians can begin to think about and reflect on how they will individually and collectively, as a profession, contend with cyberbullying in their practice.

\section{Summary}

Cyberbullying is a growing problem that is acknowledged by caregivers as needing increased attention. Despite this, many caregivers believe that cyberbullying is not as harmful as other forms of bullying. It needs to be noted also that some researchers of bullying view cyberbullying as an extension of traditional bullying rather than a separate phenomenon (Espelage et al., 2013). As cyberbullying is researched further, some links are being established between the two types of bullying (Espelage et al., 2013; Kowalski \& Limber, 2007) that suggest that they may be more closely related than previously thought. This assertion needs continued research because its implications may help inform future interventions for or means of conceptualizing the problem of cyberbullying.

The study also revealed differences between caregivers of different age groups in their familiarity with the media used for cyberbullying. This finding indicates a greater need for education and outreach to caregivers of all ages and backgrounds. Caregivers also believe that greater involvement by schools and government can be the most helpful in curbing 
cyberbullying. While schools and legislation can play important policy and implementation roles in preventing and combating cyberbullying, the role of parents needs to be given consideration as well. Results from the study found that participants believed that involvement by parents to be as effective as having no involvement at all. The lack of importance and belief placed in caregivers is an area that needs both research and intervention. The question that arises is, Are parents feeling as hopeless as well as helpless as their children who are bullied? The parents may be feeling overwhelmed by the internet-influenced daily changing world and its communication system. It will be especially important for diverse types of research to focus on developing specific guidelines for training and educating caregivers about cyberbullying and to inform the development of law and ethics about internet communications. 


\section{References}

Belsey, B. (2004). Cyberbullying. Canadian Teacher Magazine, 2, 18-19.

Beran, T., \& Li, Q. (2005). Cyber-harassment: A new method for an old behavior. Journal of Educational Computing Research, 32, 265-277.

Beran, T., \& Li, Q. (2007). The relationship between cyberbullying and school bullying. Journal of Student Wellbeing, 1, 15-33.

Berson, I.R., Berson, M.J., \& Ferrom, J.M. (2002). Emerging risks of violence in the digital age: Lessons for educators from an online study of adolescent girls in the United States. Journal of School Violence, 1(2), 51-72.

Blair, J. (2003). New breed of bullies torment their peers on the Internet. Education Week, 22, 6.

Boulton, M.J., \& Underwood, K. (1992). Bully/victim problems among middle school children. British Journal of Educational Psychology, 62, 73-87.

Braun, V., \& Clarke, V. (2006). Using thematic analysis in psychology. Qualitative Research in Psychology, 3, 77-101.

Brenner, J. (2013). Pew Internet: Social Networking. Retrieved June 30, 2013 from http://pewinternet.org/Commentary/2012/March/Pew-Internet-Social-Networking-fulldetail.aspx

Cashmore, P. (2006). MySpace hits 100 million accounts. Retrieved March 10, 2008 from http://mashable.com/2006/08/09/myspace-hits-100-million-accounts/

CBS Washington. (November 15, 2012). Census: U.S. Poverty Rate Spikes, Nearly 50 Million Americans Affected. Retrieved September 30, 2013 from http://washington.cbslocal.com/2012/11/15/census-u-s-poverty-rate-spikes-nearly-50million-americans-affected/ 
Cheng, A., \& Evans, M. (June 2009). Inside Twitter - An in-depth look inside the Twitter world. Sysomos. Retrieved March 4, 2012 from http://www.sysomos.com/insidetwitter/

Chibbaro, J.S. (2007). School counselors and the cyberbully: Interventions and implications. Professional School Counseling, 11(1), 65-68.

Cohen, J. (1992). A power primer. Quantitative Methods in Psychology, 112, 1, 155-159.

Consumer Reports. (May 10, 2011). Five million Facebook users are 10 or younger. Retrieved March 4, 2012 from http://news.consumerreports.org/electronics/2011/05/five-millionfacebook-users-are-10-or-younger.html

Crum, C. (March 28, 2011). Skype hits 30 million users online record. Retrieved March 4, 2012 from http://www.webpronews.com/skype-hits-30-million-users-online-record-2011-03

Cyberbullying Research Center. (2012). Retrieved on March 22, 2012 from http://www.cyberbullying.us/

Daues, J. (May 29, 2012). MO Supreme Court strikes down part of “Megan's Law”. Retrieved September 12, 2012 from http://articles.kspr.com/2012-05-29/mo-supremecourt_31891231

Dehue, F., Bolman, C., \& Völlink, T. (2008). Cyberbullying: Youngsters’ experiences and parental perception. CyberPsychology \& Behavior, 11(2), 217-223.

Diamanduros, T., Downs, E. , \& Jenkins, S. J. (2008). The role of school psychologists in the assessment, prevention, and intervention of cyberbullying. Psychology in the Schools, 45(8), 693-704.

Espelage, D.L., Rao, M.A., \& Craven, R. (2013). Relevant theories for cyberbullying research. In Bauman, S., Walker, J., \& Cross, D. (Eds). Principles of cyberbullying research: Definition, methods, and measures. NY \& London: Routledge. 
Espelage, D. \& Swearer, S. (2003). Research on school bullying and victimization: What have we learned and where do we go from here?. School Psychology Review, 32(3), 365-368.

Facebook Community Standards. (2012). Facebook Community Standards. Retrieved from http://www.facebook.com/communitystandards/

Facebook Help Center. (2012). Information for parents and educators. Retrieved from https://www.facebook.com/help/parents

Facebook Safety Center. (2012). Safety and you: Teens. Retrieved from http://www.facebook.com/safety/groups/teens/

Fazackarley, J. (October 27, 2010). Cyberbullying is parents' biggest fear. Retrieved May 6, 2013 from http://digitaljournal.com/article/299346

Gaillard, K. (October 26, 2010). More African American grandparents are raising children. Examiner. Retrieved February 26, 2013 from http://www.examiner.com/article/moreafrican-american-grandparents-are-raising-grandchildren

Glover, D., Gough, G., Johnson M., \& Cartwright, N. (2000). Bullying in 25 secondary schools: Incidence, impact and intervention. Educational Research, 42, 141-156.

Goddard, C. (2008).H8@ Skul: Cyber world bullying. Education Digest: Essential Readings Condensed for Quick Review, 73(7), 4-9.

Grohol, J. (2008). Online time important to teen development $\mid$ Psych Central News. Retrieved December 10, 2010, from http://psychcentral. Com/news/2008/11/20/online-timeimportant-to-teen-development/3386. Html.

Halligan, J. (2010). Ryan's Story. Retrieved March 22, 2011 from http://www.ryanpatrickhalligan.org 
Harcey, T. D. (2009). A phenomenological study of the nature, prevalence, and perceptions of cyberbullying based on student and administrator responses. Dissertation Abstracts International Section A: Humanities and Social Sciences, 69(7), 2543.

Harding, L. (April 12, 2008). They were ganging up on her, calling her fat and a wh***:the cyberbullying that got out of control. Daily Mail. Retrieved September 12, 2012 from http://www.dailymail.co.uk/home/you/article-558901/They-ganging-calling-fat-wh_- cyber-bullying-got-hand.html

Hoffman, J. (December 4, 2010). As bullies go digital, parents play catch up. New York Times. Retrieved May 28, 2013 from http://www.nytimes.com/2010/12/05/us/05bullyhtml?ref= homepage \&src $=$ me\&pagewanted $=$ all\&_r $=0$

Hoover, J. H. , Oliver, R. , \& Hazler, R. J. (1992). Bullying: Perceptions of adolescent victims in the 93idwestern USA. School Psychology International, 13(1), 5.

Hu, W. (October 1, 2010). Legal debate swirls over charges in a student's suicide. The New York Times. Retrieved March 22, 2012 from http://www.nytimes.com/2010/10/02/nyregion/02suicide.html

Human Rights Watch. (2001). Hatred in the hallways: Violence and discrimination against lesbian, gay, bisexual, and transgender students in the U.S. New York: Author.

Johnson, R.B., Onwuegbuzie, A.J., \& Turner, L.A. (2007). Toward a definition of mixed methods research. Journal of Mixed Methods Research, 1(2), 112-113.

Jorgensen, J. (June 20, 2010). NH gets tough on cyberbullying. Eagle Tribune. Retrieved October 15, 2013 from http://www.eagletribune.com/latestnews/x1703932250/NH-gets-tough-oncyberbullying 
Juvonen, J. , \& Gross, E. F. (2008). Extending the school grounds?-Bullying experiences in cyberspace. Journal of School Health, 78(9), 496-505.

Kaplan, A.M., \& Haenlein, M. (2010). Users of the world unite! The challenges and opportunities of social media. Business Horizons, 53, 1, 59-68.

Katzer, C. , Fetchenhauer, D. , \& Belschak, F. (2009). Cyberbullying: Who are the victims?: A comparison of victimization in internet chatrooms and victimization in school. Journal of Media Psychology: Theories, Methods, and Applications, 21(1), 25-36.

Kazeniac, A. (February 9, 2009). Social networks: Facebook takes over the top spot, Twitter climbs. Compete Pulse. Retrieved March 4, 2012 from http://blog.compete.com/2009/02/09/facebook-myspace-twitter-social-network/

Kelly, J. (May 24, 2010). Instant messaging: This conversation is terminated. BBC News Magazine. Retrieved March 4, 2012 from http://news.bbc.co.uk/2/hi/uk_news/magazine/8698174.stm

Koman, R. (December 21, 2008). Megan's Law: Mo. Prosecutors using new cyberbullying laws. Retrieved September 12, 2012 from http://www.zdnet.com/blog/government/meganslaw-mo-prosecutors-using-new-cyberbullying-laws/4233

Kowalski, R. M. , \& Limber, S. P. (2007). Electronic bullying among middle school students. Journal of Adolescent Health, 41(6), 22-30.

Law, D.M, Shapka, J.D., Hymel, S., Olson, B., \& Waterhouse, T. (2012). The changing face of bullying: An empirical comparison between traditional and internet bullying and victimization. Computers in Human Behavior, 28, 226-232.

Leary, M.R., Kowalski, R.M., Smith, L., \& Phillips, S. (2003). Teasing, rejection, and violence: Case studies of the school shootings. Aggressive Behaviors, 29, 202-214. 
Li, Q. (2006). Cyberbullying in schools: A research of gender differences. School Psychology International, 27(2), 157-170.

Miller, C. (August 25, 2009). Who’s driving Twitter's popularity? Not teens. The New York Times. Retrieved March 4, 2012 from http://www.nytimes.com/2009/08/26/technology/internet/26twitter.html?_r=1

Moore, H. (November 14, 2012). Petraeus scandal: a readers' guide to the clandestine soap opera and its cast. The Guardian. Retrieved December 12, 2012 from http://www.guardian.co.uk/world/2012/nov/14/petraeus-scandal-readers-guide-cast

MySpace reporting content. (2012). Retrieved on December 13, 2012 from http://myspace.desk.com/customer/portal/articles/518499-reporting-content

MySpace terms of use agreement. (2012). Retrieved on March 5, 2012 from http://www.myspace.com/Help/Terms?pm_cmp=ed_footer

Nakamoto, J., \& Schwartz, D. (2010). Is peer victimization associated with academic achievement? A meta-analytic review. Social Development, 19, 221-242.

Nansel, T.R., Overpeck, M.D., Haynie, D.L., Ruan, W.J., \& Scheidt, P.C. (2003). Relationships between bullying and violence among US youth. Archives of Pediatrics \& Adolescent Medicine, 157, 348-353.

Nishina, A., Juvoven, J., \& Witkow, M.R. (2005). Sticks and stones may break my bones, but names will make me feel sick: the psychosocial, somatic, and scholastic consequences of peer harassment. Journal of Clinical Child and Adolescent Psychology, 3(1), 37-48.

Olweus, D. (1993). Bullying at school: What we know and what we can do. Oxford, UK: Blackwell Publishers. 
Oreskovic, A. (January 23, 2012). Exclusive: YouTube hits 4 billion daily video views. Retrieved March 4, 2012 at http://www.reuters.com/article/2012/01/23/us-google-youtubeidUSTRE80M0TS20120123

Patchin, J.W., \& Hinduja, S. (2010). Changes in adolescent online social networking behaviors from 2006 to 2009. Computers in Human Behavior, 26, 1818-1821.

Perez-Peña, R. (January 6, 2011). Christie signs tougher law on bullying in schools. The New York Times. Retrieved March 22, 2012 from http://www.nytimes.com/2011/01/07/nyregion/07bully.html

Peskin, M.F., Tortolero, S.R., \& Markham, C.M., (2006). Bullying and victimization among Black and Hispanic adolescents. Adolescence, 411(163), 467-484.

Pilkington, E. (September 30, 2010). Tyler Clementi, student outed as gay on the internet, jumps to his death. The Guardian. Retrieved March 22, 2012 from http://www.guardian.co.uk/world/2010/sep/30/tyler-clementi-gay-student-suicide

Pilkington, N.W., \& D’Augelli, A.R. (1995). Victimization of lesbian, gay and bisexual youth in community settings. Journal of Community Psychology, 23(1), 33-56.

Pokin, S. (November 11, 2007). 'My Space' hoax ends with suicide of Dardenne Prairie teen. St. Louis Post-Dispatch. Retrieved September 12, 2012 from http://www.stltoday.com/suburban-journals/stcharles/news/stevepokin/my-space-hoaxends-with-suicide-of-dardenne-prairie-teen/article_0304c09a-ab32-5931-9bb3$210 \mathrm{a} 5 \mathrm{~d} 5 \mathrm{dbd} 58 . \mathrm{html}$

Protalinski, E. (2012). Facebook has over 845 million users. http:/www.zdnet.com/blog/facebook/facebook-has-over-845-millionusers/8332Retrieved February 28, 2012. 
Raacke, J. \& Bonds-Raacke, J. (2008). MySpace and Facebook: Applying the uses and gratifications theory to exploring friend-networking sites. Cyberpsychology \& Behavior, 11(2), 169-174.

Raskauskas, J. \& Stoltz, A.D., (2007). Involvement in traditional and electronic bullying among adolescents. Developmental Psychology, 43(3), 564-575.

Riessman, C.K. (2008). Narrative methods for the human sciences. Los Angeles: Sage Publications.

Rigby, K. (2000). Effects of peer victimization in schools and perceived social support on adolescent well-being. Journal of Adolescence, 23, 57-68.

Rudin, S. (Producer), Brunetti, D. (Producer), De Luca, M. (Producer), Chaffin, C. (Producer), \& Fincher, D. (Director). (2010). The Social Network [Motion picture]. United States: Columbia Pictures

Rundquist, J. (March 11, 2012). 6 months into N.J. law to halt bullying, a survey takes a look at how it's working. NJ.com. Retrieved December 12, 2012 from http://www.nj.com/news/index.ssf/2012/03/6_months_into_nj_law_to_halt_b.html

Seals, D., \& Young, J. (2003). Bullying and victimization: Prevalence and relationship to gender, grade level, ethnicity, self-esteem and depression. Adolescence, 38(152), 735-747.

Skype terms of use. (2012). Your obligations. Retrieved December 13, 2012 from http://beta.skype.com/en/legal/tou/\#6

Slee, P. T. (1996). The P.E.A.C.E pack: A programme for reducing bullying in our schools. Australian Journal of Guidance and Counselling, 6, 63-69.

Slonje, R., \& Smith, P.K. (2007). Cyberbullying: Another main type of bullying?. Scandinavian Journal of Psychology, 49, 376-385. 
Slovak, K., \& Singer, J.B. (2011). School social workers' perceptions of cyberbullying. Children \& Schools, 33, 1, 5-16.

Smith, P. , Mahdavi, J. , Carvalho, M., \& Tippett, N. (2006). An investigation into cyberbullying, Its forms, awareness and impact, and the relationship between age and gender in cyberbullying. Report to the Anti-Bullying Alliance.

Smith, P. K., Madsen, K. C. , \& Moody, J. C. (1999). What causes the age decline in reports of being bullied at school? Towards a developmental analysis of risks of being bullied. Educational Research, 41(3), 267-285.

Smith, P. K., Mahdavi, J , Carvalho, M , Fisher, S, Russell, S., \& Tippett, N. (2008). Cyberbullying: Its nature and impact in secondary school pupils. Journal of Child Psychology and Psychiatry, 49(4), 376-385.

Steel, E. (September 19, 2011). Myspace owners Justin Timberlake, SpecificMedia shrink redesign party. Wall Street Journal. Retrieved March 4, 2012 from http://online.wsj.com/article/SB10001424053111904106704576579263962636624.html

Swearer, S.M, Turner, R.K., Givens, J.E., \& Pollack, W.S. (2008). “You're so gay!” Do different forms of bullying matter for adolescent males? School Psychology Review, 37(2), 160173.

Taylor, C. (June 27, 2011). Social networking 'utopia' isn't coming. CNN. Retrieved March 4, 2012 from http://articles.cnn.com/2011-0627/tech/limits.social.networking.taylor_1_twitter-users-facebook-friendsconnections?_s=PM:TECH 
Techtree News Staff. (2008). Facebook: Largest, fastest growing social network. Retrieved March 4, 2012 from http://archive.techtree.com/techtree/jsp/article.jsp?article_id=92134\&cat_id=643

Tokunaga, R.S. (2010). Following you home from school: A critical review and synthesis of research on cyberbullying victimization. Computers in Human Behavior, 26, 277-287.

Twitter. (2012). The twitter rules. Retrieved December 13, 2012 from https://support.twitter.com/groups/33-report-a-violation/topics/121-guidelines-bestpractices/articles/18311-the-twitter-rules

Twitter safety tips for teens. (2012). Safety tips for teens. Retrieved December 13, 2012 from http://support.twitter.com/groups/33-report-abuse-or-policy-violations/topics/166-safetycenter/articles/20169990-safety-tips-for-teens

US Census. Overview of Race and Hispanic Origin 2010. 2011. Retrieved from http://www.census.gov/prod/cen2010/briefs/c2010br-02.pdf

Waasdorp, T.E., \& Bradshaw, C.P. (2011). Examining student responses to frequent bullying: A latent class approach. Journal of Educational Psychology, 103, 2, 336-352.

Walker, J. (2010, May 23). Bill Belsey: Pioneer cyberbullying activist. Retrieved from http://www.cyberbullyingnews.com/2010/05/bill-belsey-pioneer-cyberbullying-activist/

Williams, K.R., \& Guerra, N.G. (2007). Prevalence and predictors of Internet bullying. Journal of Adolescent Health, 41, 851-858.

Williams, A. L., \& Merten, M. J. (2008). A review of online social networking profiles by adolescents: Implications for future research and intervention. Adolescence (San Diego): An international quarterly devoted to the physiological, psychological, psychiatric, sociological, and educational aspects of the second decade of human life, 43(170), 22. 
Windows Code of Conduct. (2012). Code of conduct. Retrieved December 13, 2012 from http://windows.microsoft.com/en-US/windows-live/code-of-conduct

Ybarra, M.L. (2004). Linkages between depressive symptomatology and Internet harassment among young regular Internet users. CyberPsychology \& Behavior, 7, 247-257.

Ybarra, M.L., Diener-West, M., \& Leaf, P. J. (2007). Examining the overlap in internet harassment and school bullying: Implications for school intervention. Journal of Adolescent Health, 41(6S), 42-50.

YouTube Community Guidelines. (2012). Retrieved March 4, 2012 from http://www.youtube.com/t/community_guidelines

YouTube Safety Center. (2012). Retrieved December 13, 2012 from http://support.google.com/youtube/bin/answer.py?hl=en\&answer=126266

Zetter, K. (July 2, 2009). Judge acquits Lori Drew in cyberbullying case, overrules jury. Retrieved September 12, 2012 from http://www.wired.com/threatlevel/2009/07/drew_court/

Zickuhr, K. (September 25, 2013). Who's not online and why. Retrieved September 30, 2013 from http://pewinternet.org/Reports/2013/Non-internet-users.aspx 
Appendix A: Demographic Questionnaire

Please select the category that best describes you. For open ended responses, please type the response that best answers the question.

Age:

22-32 years old

33-43 years old

44-54 years old

55-65 years old

Sex:

Male

Female

Other

How do you identify yourself (Check one):

African American

Asian American

American Indian/Native American

Latino/Hispanic

Middle Eastern

White American

Biracial/Multiracial

\section{Marital Status (Check one):}

Single

In a relationship(not married)

Married

Separated

Divorced

Widowed

Relationship to child/children under your care (Check one):

I am the parent.

I am the grandparent.

I am the legal guardian.

\section{Highest Level of Education Attained (check one):}

Did not complete high school

Graduated high school or GED Diploma

Some college

Associate Degree

Bachelor's Degree 
Master's Degree

Doctorate Degree

Other (If other, what education did you attain?)

\section{Class and Income}

Unemployed/Part-time Employed

Working Class, poor

Working Class, middle to high income

Middle Class

Upper Middle Class

Rich $500 \mathrm{~K}$

Very Rich Million dollars and above

Geographic location (Check one):

Rural

Small town

Small city

Large metropolitan city

State of Residence in the United States:

\section{Number of Children:}

Grade/s of Child/Children (include all children attending elementary school through college; so it's possible that you'll fill more than one blank):

$1^{\text {st }}$ through $4^{\text {th }}$ grade

$5^{\text {th }}$ through $8^{\text {th }}$ grade

$9^{\text {th }}$ through $12^{\text {th }}$ grade

$1^{\text {st }}$ year of undergraduate school through $4^{\text {th }}$ year of undergraduate school 
Appendix B: Cyberbullying Questionnaire

\section{Perceptions and Awareness of Cyberbullying Questionnaire}

Please select the response that best describes your beliefs. For open ended questions, please type in the answer(s) that best answer the question

1. What does cyberbullying mean for you?

2. Cyberbullying is a problem at my child's/children's school.
a. Strongly Disagree
b. Disagree
c. Agree
d. Strongly Agree

3. Cyberbullying occurs during school time.
a. Strongly Disagree
b. Disagree
c. Agree
d. Strongly Agree

4. Cyberbullying occurs outside of school.
a. Strongly Disagree
b. Disagree
c. Agree
d. Strongly Agree

5. Cyberbullying is an issue that needs increased attention from parents.
a. Strongly Disagree
b. Disagree
c. Agree
d. Strongly Agree

6. How do you see cyberbullying as a problem?

7. Cyberbullying is more harmful than bullying in the schoolyard and hallways.
a. Strongly Disagree
b. Disagree
c. Agree
d. Strongly Agree

8. I have discussed cyberbullying with my child 

a. Strongly Disagree
b. Disagree
c. Agree
d. Strongly Agree

9. My child is as likely to talk to me about cyberbullying as he or she is to talk to me about bullying in the schoolyard and hallways.
a. Strongly Disagree
b. Disagree
c. Agree
d. Strongly Agree

10. I do not know whether cyberbullying is addressed at my child's/children's school. (reverse item)
a. Strongly Disagree
b. Disagree
c. Agree
d. Strongly Agree

11. I believe that cyberbullying can cause psychological harm to my child/children.
a. Strongly Disagree
b. Disagree
c. Agree
d. Strongly Agree

12. Cyberbullying occurs less frequently than bullying in my child's/children's schoolyard and hallways. (reverse item)
a. Strongly Disagree
b. Disagree
c. Agree
d. Strongly Agree

13. I have heard or read that cyberbullying has contributed to suicide among students.
a. Strongly Disagree
b. Disagree
c. Agree
d. Strongly Agree

14. I believe it is important to monitor my child's use of the internet
a. Strongly Disagree
b. Disagree
c. Agree
d. Strongly Agree

15. Please list the different ways, if any, you monitor your child's use of the internet 
16. I believe it is important to place restrictions on my child's use of the internet

a. Strongly Disagree

b. Disagree

c. Agree

d. Strongly Agree

17. Please list the different restrictions, if any, you place on your child's use of the internet

18. Please note in the lines below the different types of media through which cyberbullying occurs (i.e., specific websites, devices used for messaging, etc.).

19. I am familiar with Facebook.
a. Strongly Disagree
b. Disagree
c. Agree
d. Strongly Agree

20. I am familiar with MySpace.
a. Strongly Disagree
b. Disagree
c. Agree
d. Strongly Agree

21. I am familiar with instant messaging services (e.g., MSN messenger).
a. Strongly Disagree
b. Disagree
c. Agree
d. Strongly Agree

22. I am familiar with Twitter.
a. Strongly Disagree
b. Disagree
c. Agree
d. Strongly Agree

23. I am familiar with YouTube.
a. Strongly Disagree
b. Disagree
c. Agree 


\section{d. Strongly Agree}

24. I am familiar with text messaging.
a. Strongly Disagree
b. Disagree
c. Agree
d. Strongly Agree

25. I have not learned about cyberbullying from the news on radio or television. (reverse item)
a. Strongly Disagree
b. Disagree
c. Agree
d. Strongly Agree

26. My child's/children's school has informed me about cyberbullying.
a. Strongly Disagree
b. Disagree
c. Agree
d. Strongly Agree

27. I have learned about cyberbullying from my child/children.
a. Strongly Disagree
b. Disagree
c. Agree
d. Strongly Agree

28. I have done my own research/investigation about cyberbullying.
a. Strongly Disagree
b. Disagree
c. Agree
d. Strongly Agree

29. Please list any other ways through which you have learned about cyberbullying.

30. When a youth is cyberbullied, what do I believe are some obstacles for him/her for getting help?

31. Laws or school policies currently in place address cyberbullying adequately. 

a. Strongly Disagree
b. Disagree
c. Agree
d. Strongly Agree

32. Schools should be proactive in addressing cyberbullying.
a. Strongly Disagree
b. Disagree
c. Agree
d. Strongly Agree

33. Schools' increased involvement in addressing cyberbullying would not significantly reduce cyberbullying.
a. Strongly Disagree
b. Disagree
c. Agree
d. Strongly Agree

34. Parents should be more proactive in addressing cyberbullying with their child/children (whether their child is a victim or a cyberbully).
a. Strongly Disagree
b. Disagree
c. Agree
d. Strongly Agree

35. Parents' involvement in addressing cyberbullying would not reduce their child/children's cyberbullying, whether as a victim or as a cyberbully. (reverse item).
a. Strongly Disagree
b. Disagree
c. Agree
d. Strongly Agree

36. More laws should be passed to prevent or punish cyberbullying.
a. Strongly Disagree
b. Disagree
c. Agree
d. Strongly Agree

37. Please list any additional ways you think that cyberbullying could be better addressed. 
Appendix C: Informed Consent

\title{
Parents' Perceptions and Awareness of Cyberbullying Experiences
}

\author{
Principal Investigator: $\quad$ Bryan Clarke \\ Doctoral Student \\ Department of Clinical Psychology \\ Antioch University New England \\ 40 Avon St, Keene, NH, 03431 \\ E-mail: \\ BClarke@antioch.edu
}

My name is Bryan Clarke and I am a doctoral candidate in the Department of Clinical Psychology at Antioch University New England in Keene, NH. As part of my doctoral work, I am asking you to take part in a research project investigating adult perceptions and awareness of cyberbullying experiences of youth.

You are being asked to be a volunteer in a research study. The purpose of this study is to better understand the perceptions and level of awareness that adults have with regards to cyberbullying. If you decide to participate in this study, your part will involve completing this online questionnaire that should take between 10-15 minutes.

While you will not experience any direct benefits as a result of your participation, the information that you provide will help us to better understand the gaps in awareness that adults have around cyberbullying. There is little anticipated risk to individuals who participate in this research. This study is entirely anonymous - no identifying information will be collected about you, or the computer or Internet service provider through which you are accessing this website. You will not receive anything in exchange for participation. Additionally, nothing is expected from you, other than responses to questions, if you decide to participate.

Your participation in this study is voluntary. You can stop taking the survey at any time. You have the right to change your mind and leave the study at any time without giving any reason, and without penalty, by closing the window. Any new information that may make you change your mind about being in this study will be given to you. You do not waive any of your legal rights by signing this consent form.

It is not anticipated that participating in this survey will cause any stress. If you have concerns about your rights as a participant, you may contact Dr. Katherine Clarke, Chair of the Antioch University New England Institutional Review Board at 603-283-2162, or Dr. Stephen Neun, Vice President of Academic Affairs, 603-283-2150. If you have any questions about this survey, please contact me at BClarke@, antioch.edu

Once again, your participation is greatly appreciated.

Bryan Clarke 